\title{
SIMULATION OF FATE \& TRANSPORT OF CONTAMINANTS IN GROUNDWATER FOR SUPPORTING SITE ASSESSMENT
} by

\author{
Mubashar Abbasi, BSc
}

\author{
B. Sc. Department of City \& Regional Planning, (Hons.) \\ University of Engineering \& Technology, Lahore, Pakistan, 2001
}

\author{
A Project \\ presented to Ryerson University \\ in partial fulfillment of the \\ requirements for the degree of \\ Master of Engineering \\ in the Program of \\ Civil Engineering
}

Toronto, Ontario, Canada, 2010

CMubashar Abbasi, 2010

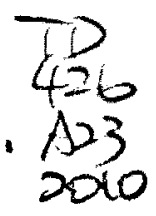




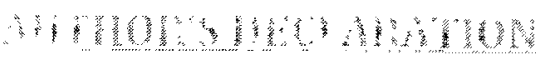

1 hereby declare that I am the sole authority of this project.

I authorize Ryerson University to lend this project to other institutions or individuals for the purpose of scholarly research.

Signature

I further authorize Ryerson University to reproduce this project by photocopying or by other means, in total or in part, at the request of other institutions or individuals for the purpose of scholarly research.

Signature

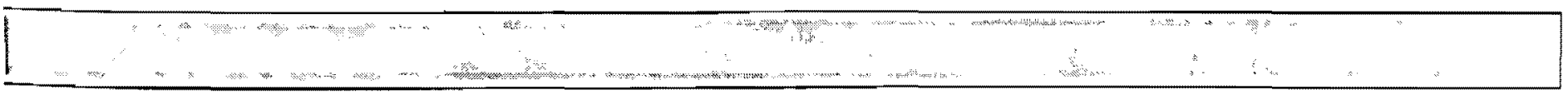




\title{
SIMULATION OF FATE \& TRANSPORT OF CONTAMINANTS IN GROUNDWATER FOR SUPPORTING SITE ASSESSMENT
}

\author{
Master of Engineering, 2010 \\ Mubashar Abbasi \\ Civil Engineering Program \\ Ryerson University
}

\begin{abstract}
Computcr simulations have become a useful part of mathomatical modeling of many natural systems in science and engincering. Simulations can be used to explore and gain new insights into new technology, and to estimate the performance of systems too complex for analytical solutions. BIOPLUME III is a numerical two-dimensional modcl that tracks the fate and transport of aromatic hydrocarbons. To help the environmental professional with the data management, visualization, and decision making tasks involved. Interpretations based on model analyses must recognize the significance of uncertainties in input data. Models of groundwater systems should be regarded as just one tool among many that can be used in the analysis of a ground-water quality problem. Numerical simulation can help the analyst integrate available data, evaluate conceptual models, test hypotheses pertaining to flow and quality changes, and predict system responses to alternative stresses. The models do not replace ficld data, but they help to guide the design of a more cffective and more efficient data-collcction program.
\end{abstract}


(n)

(1)

\section{ACKNOWLEDGEMENTS}

The author acknowledges his indebtedness and sincere gratitude to his supervisor Dr. He $\mathrm{Li}$, Assistant Professor, Department of Civil Engineering, Ryerson University for his continuous guidance, assistance and spirited encouragement through the entire course of this project work.

The author wishes to express his sincere thanks to his friends for their support during this time. 


\section{TABLE OF CONTENTS}

AUTHOK'S DECLARATION.

ABSTRACT

ACKNOWLEDGEMENTS. iv

TABLE OF CONTENTS v

LIST OF TABLES viii

LIST OF FIGURES ix

CHAPTER 1

INTRODUCTION 1

General . .1

Groundwater

Hydrologic Cycle

Groundwater as a Resource

Management of Groundwater.

Sources of Groundwater Contamination

Ground Water Remediation

Overview

Objectives.....

CHAPTER 2



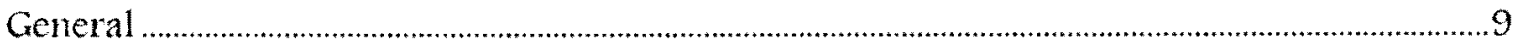

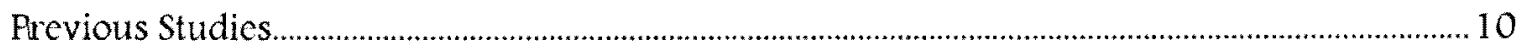

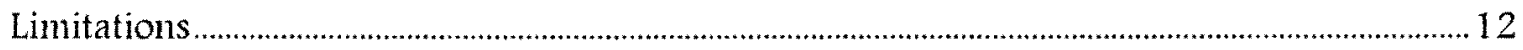

CHAPTER 3

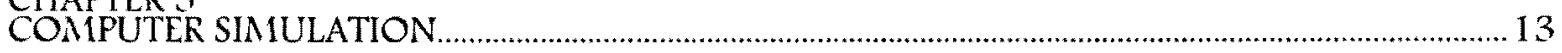

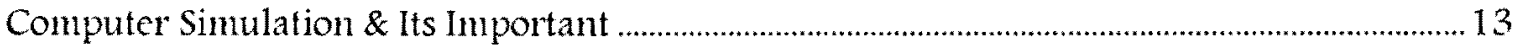

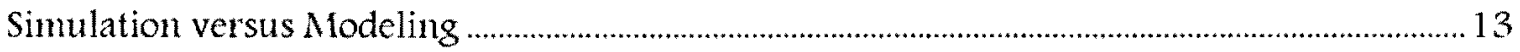

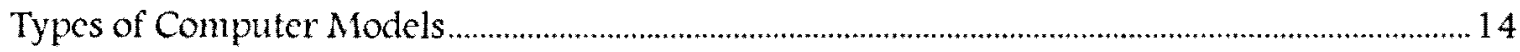




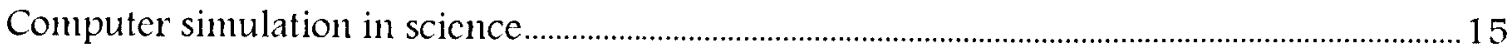

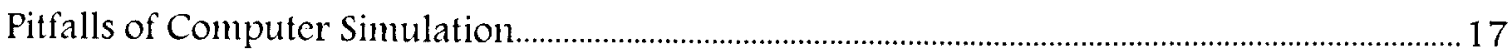

Model Calibration Techniques........................................................................................................ 1 $7^{\bullet}$

Fate and Transport Model Reporting Requirements ...........................................................................2 20

CHAPTER 4

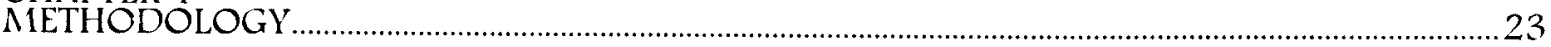

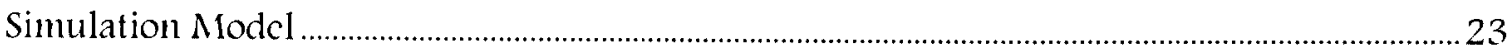

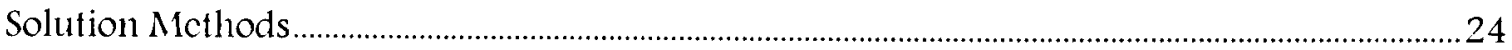

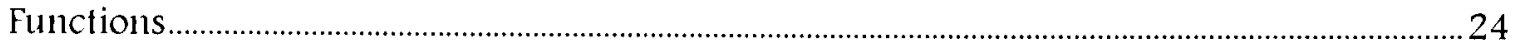

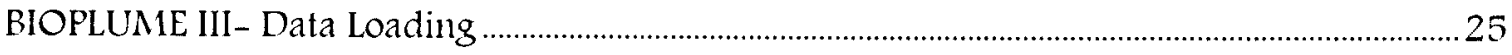



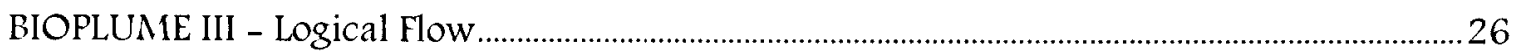



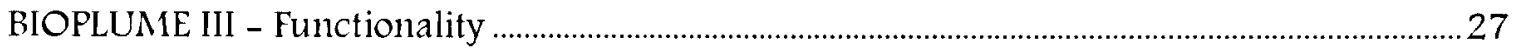

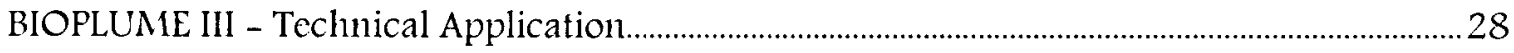

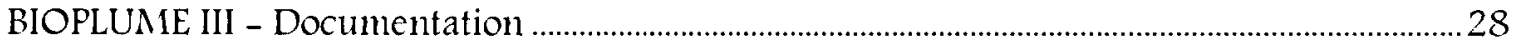





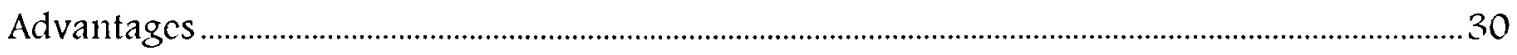

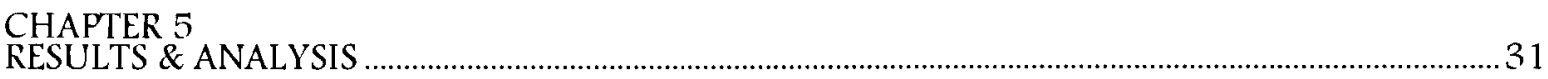

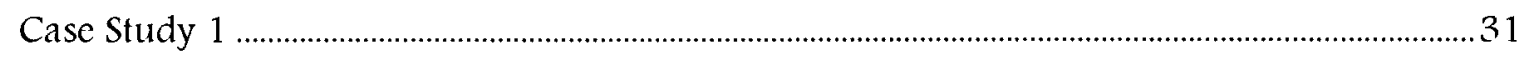

Evaluation of Natural Attenuation of Chlorinated Solvents in Ground Water...........................31

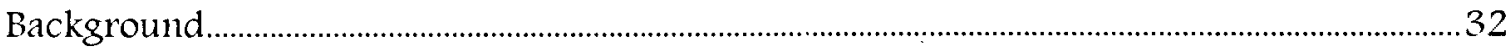



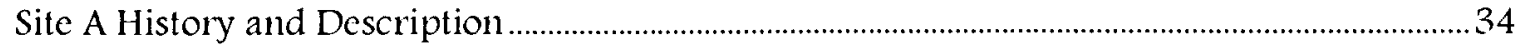

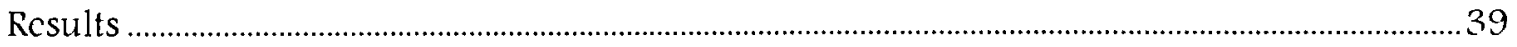

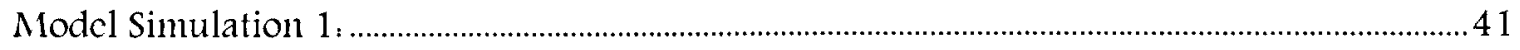




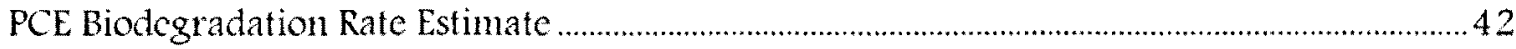

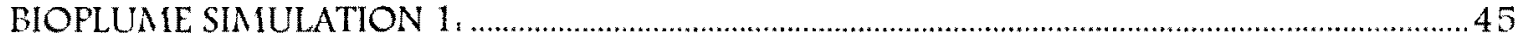

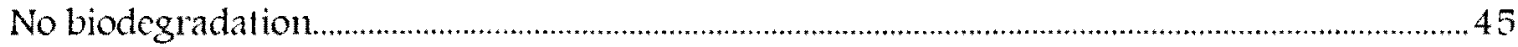

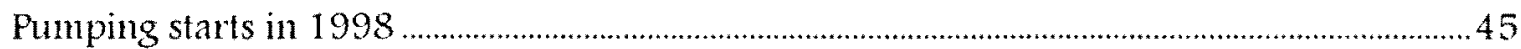

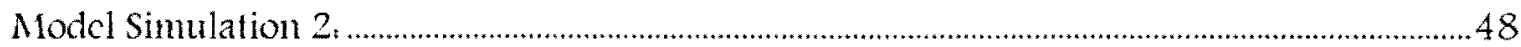

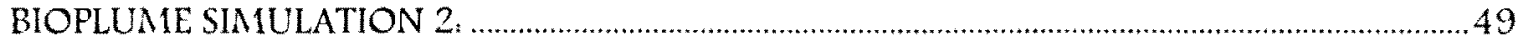



Model Simulation 3: Biodegradation at $-0.6 \mathrm{yr}-1$ with Ground Water Extraction Starting in

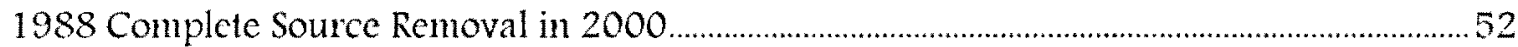

BIOPLUME SINIULATION 3:Biodegradation at -0.6 per year.Pumping starts in $1998.90 \%$

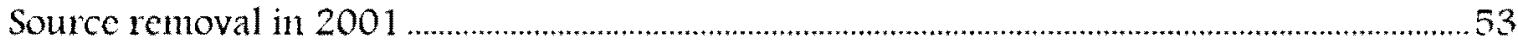
CHAPTER 6

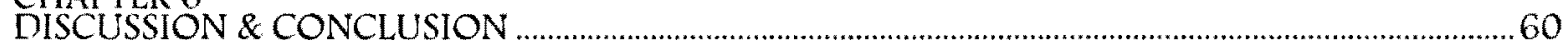

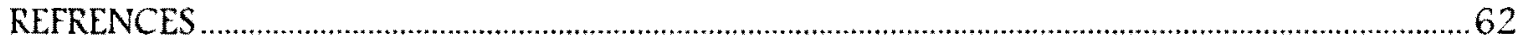

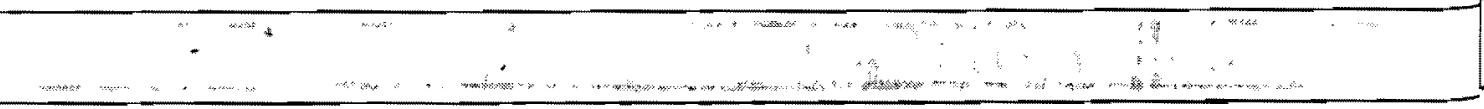




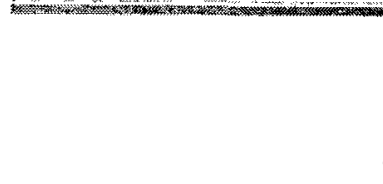

.

\section{LIST OF TABLES}

Table 1 Part of modeling input parameters

Table 2 Geochemistry of the Site A ground water. Monitoring well 01 U067 is a background well sifuated upgradient from the source area ground water. 40

Table 3 Concentrations of PCE as a function of distance from the source area. 43

Table 4 Spccifications of monitoring wells selected for the natural attenuation study. 44

Table 5 Comparisons of PCE concentrations (in $\mu g / L$ ) predicted by BIOPLUME III simulations for 1990 with actual 1990 field data. Simulation 1 is the simulation without biodegradation included; Simulation 2 includes biodegradation at -0.6 per year. 44 


\section{LIST OF FIGURES}

Figure 1 Kootenay National Park. Hot springs occur when groundwater is heated at depth........3

Figure 2 Sources of Groundwater Contamination ...............................................................................6

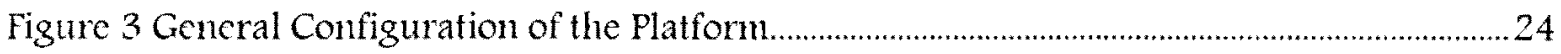

Figure 4 Platform controls to input water quality data.................................................................2.

Figure 5 Entering Well Data in the Platform ......................................................................................26

Figure 6 Reductive dehalogenation of chlorinated solvents is most favorable under sulfate or carbon dioxide reducing conditions, indicated by the arrow ...............................................................33

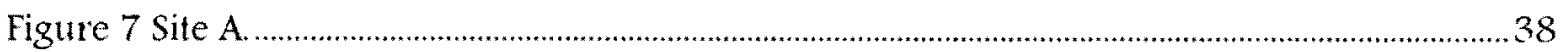

Figure 8 Relationship of two of the residential wells (green) to Site A and the location of the ground water. 38

Figure 9 Location of wells that were sampled for the natural attenuation study 39

Figure 10 BIOPLUME SIMULATION 1:1970 45

Figure 11 BIOPLUMIE SINIULATION 1,1975. 45

Figure 12 BIOPLUME SIMULATION 1:1980. 46

Figure 13 BIOPLUAE SIMULATION 1.1985 46

Figure 14 BIOPLUMIE SIMULATION 1:1990. 47

Figure 15 BIOPLUMIE SIMULATION 1:1996. 47

Figure 16 BIOPLUME SIMULATION 2: 1970 49

Figure 17 BIOPLUME SIMULATION 2: 1975 49

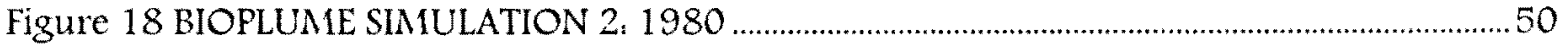

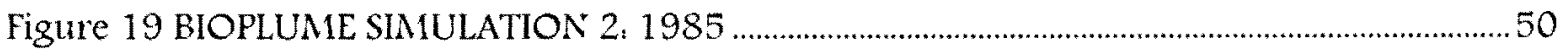

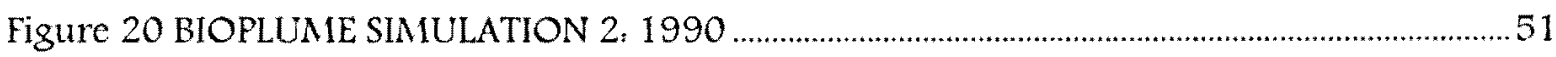

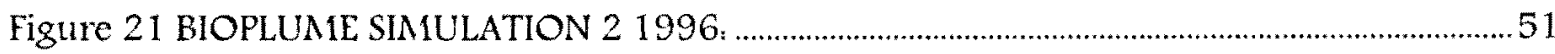

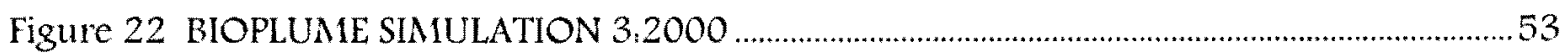

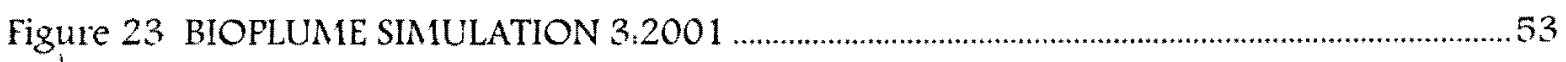

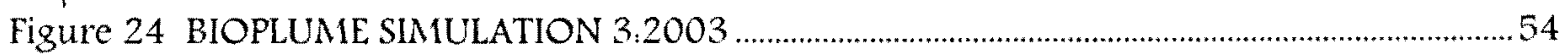

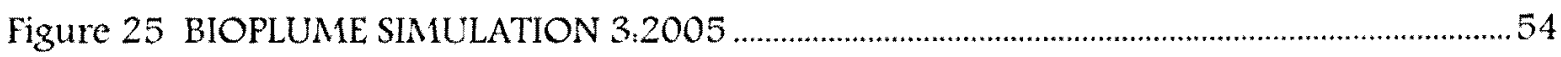

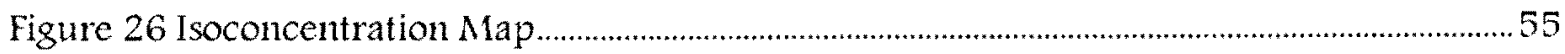

Figure 27 Contaminant Trends vs. Time in Monitoring Well 01 U108 …......................................56



Figure 29 Contaminant Trends vs. Time in Mfonitoring Well 01 U902 ….......................................58

Figure 30 Contaminant Trends vs. Time in Monitoring Well 01 U1 15 .............................................59 


\section{SIMULÁTION OF FATE \& TRANSPORT OF CONTAMINANTS IN GROUNDWATER FOR SUPPORTING SITE ASSESSMENT}

\section{CHAPTER 1}

\section{INTRODUCTION}

\section{General}

Leaks of petroleum products have been increasing over the last two decades because underground steel tanks installed in large numbers in the 1950s and 1960s have become corroded. Before 1980, most underground tanks were made of steel. Without adequate corrosion protection, up to half of them leak by the time they are 15 years old. (Environment Canada)

Groundwater dissolves many different compounds, and most of these substances have the potential to contaminate large quantities of water. For example, one litre of gasoline can contaminate 1000000 litres of groundwater. This problem is particularly severe in the Atlantic Provinces where there is a high usage of groundwater. In many cases, the problem is noticed long after the aquifer is contaminated, for example, when consumers start tasting or smelling gasoline.

In the development of policies and regulations for groundwater protection, in permitting, and in planning monitoring and remedial actions, the role of mathematical models is growing rapidly. Because water-resource management decisions should be based on technically and scientifically sound methods, quality assurance (QA) needs to be applied to groundwater modeling, both in model development and field studies, and should also play an important part in model selection. 


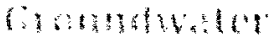

Groundwater is water which occupies the spaces between particles of soil and blocks of rock bencath our feet. Groundwater is ubiquitous; it can be found beneath the Great Plains, the Canadian Shield and mountainous terrain on both sides of the North American continent. Groundwater constitutes almost $70 \%$ of the world's freshwater supply. In comparison, lakes and rivers make up only $0.2 \%$, with the rest frozen in snow and ice. Groundwater can dissolve soluble rocks and its circulation is responsible for the formation of caves in limestone terrain. Groundwater, heated at depth, often rises to the surface to form hot springs like those at Banff and Jasper. Alta, and Radium and Fairmont, BC. (Canadian Encyclopaedia)

\section{Hytirolanic Cyds}

Groundwater interacts with lakes and rivers as part of the hydrologic cycle. The cycle begins with the formation of clouds through evaporation from the ocean, lakes, rivers, plants and soil. Precipitation from the clouds either infiltrates as groundwater recharge or is diverted to lakes and streams as surface runoff. The proportion of infiltration versus runoff is dependent on the permeability of the soil, soil moisture, the amount of vegetation, topography and climate.

Infiltrating precipitation shares the interstices of the soil with air in the zone immediately beneath ground surface. At some depth the infiltrating water will encounter the water table. Below this surface the interstices are entirely occupied by water (no air present as a scparate phase), and this is known as the groundwater zone. The region above the water table is known as the vadose zone.

Water in the groundwater zone is not stagnant and flows from regions of high water table to lower water table. In many cases, the direction of groundwater flow follows the topographic surface. Eventually, most groundwater will return to the surface of the Earth in areas of groundwater discharge such as wetlands, lakes and rivers.

The residence time of the percolating water in the vadose zone may be quite short (i.e., hours to days), depending on the depth to the water table. Conversely, the residence time of water in the groundwater zone varies greatly and transit times as short as a few days to greater than 10000 years have becn measured. In some geological materials such as sands and gravels, or highly 
fractured rock, groundwater is plentiful and migrates at a rapid rate. These geological formations are known'as aquifers and occur in various forms across Canada.

\section{Radium Hot Springs}

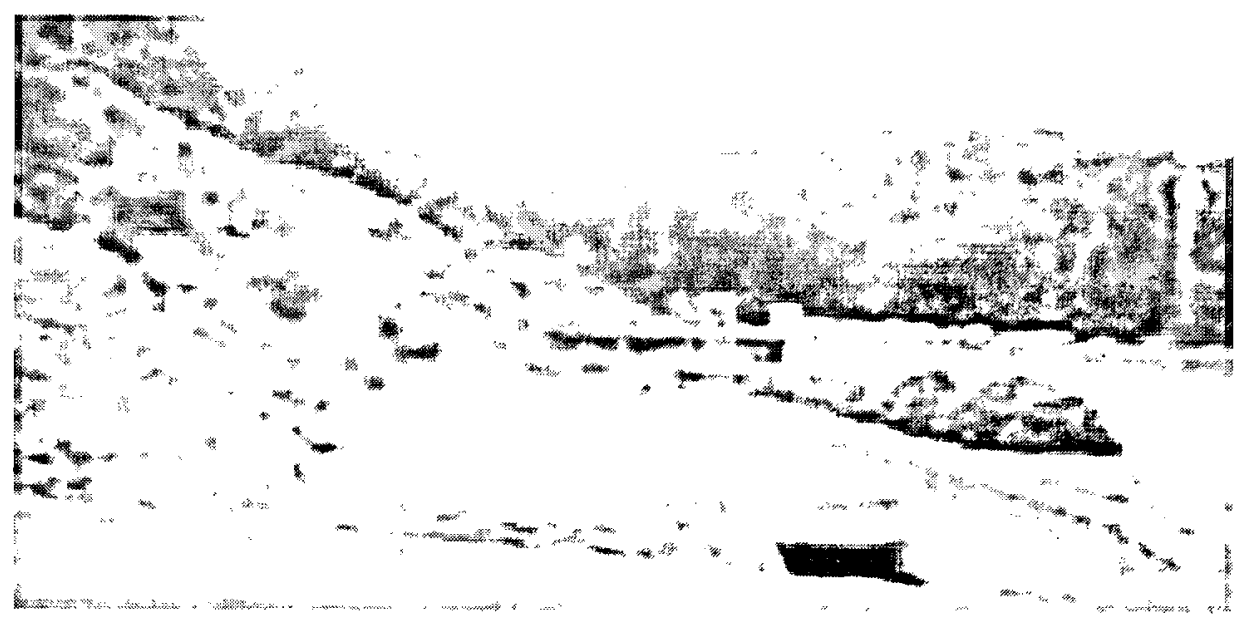

|1,

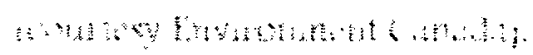

\section{Gonndibateras a Resource}

In areas where groundwater is plentiful and easily pumped, such as the aquifers in the sand plains of south-central Ontario, the large sandstone aquifers in Alberta or the valley-bottom aquifers in New Brunswick, consumption for drinking water purposes is common. Groundwater is used as a source of drinking water by approximately $25-30 \%$ of Canadians. In some provinces, such as those in the Maritimes, the domestic use of groundwater is mucl higher. For example, the provinces of New Brunswick and Prince Edward Island are 64\% and $100 \%$ reliant, respectively, on groundwater as a source of water for domestic use. Use in the Prairie Provinces ranges from 24\% in Manitoba to 54\% in Saskatchewan. In addition, 82\% of Canada's rural population depend on groundwater for domestic use. 
In addition to domestic use, groundwater is widely used in industrial and manufacturing processes and for agricultural purposes. For example, more than half of the groundwater consumed in British Columbia is done so for industrial purposes. In Mantitoba and Alberta, the majority of groundwatcr usage is by the agricultural industry.

Bccause groundwater is an integral component of the hydrologic cycle, excessive consumption can adversely affect the sustainable use of surface water. Groundwater is a renewable but limited resource. For example, over consumption of local groundwater combined with the effects of global warming and of urbanization all negatively influence the groundwater component of wetlands ecosystems. In some areas of the country, development in rural areas is now linited by the sustainability (both quantity and quality) of groundwater supplies.

ianderment of Groundwater

Management of groundwater as a resource was ceded to the provinces in the constitution act of 1867. Thus, authority to manage groundwater resources resides in provincial ministries. In practice, however, regional levels of governments often play a large role in regulating the use of groundwater through restrictions on consumptive use and industrial development. The federal government maintains a role in conducting research and providing advice to the provinces on matters related to groundwater contamination and consumption.

Sindecs of fimondivaler Contamination

Since groundwater is an unseen resource and travels more slowly than the circulation of most surface water bodies (i.e., centimetres to metres per year). groundwater contamination often goes undetected for extended periods of time. For example. some types of groundwater contamination, such as road salt, have yet to significantly impact surface water quality despite being present as groundwater contaminants for many decades. Unfortunately, groundwater contamination is often defected through the adverse smell or taste observed in water wells adjacent to the source of contamination.

The contamination of groundwater occurs through both point and non-point sources. Examples of non-point sources include road salt, agricultural chemicals, atmospheric deposition, land farming of industrial wastes and contamination from urbanization. The most 
common contaminants from these types of sources are chloride, nitrate and coliform bacteria. A survey conducted in 1992 of farm wells in Ontario found that $31 \%$ of the wells surveycd had levels of coliform bacteria above the maximum acceptable concentration (MAC), 13\% had nitrate above the MAC and $8 \%$ had detectable levels of pesticides.

Point sources of contamination often result in elevated concentrations of contaminants that are more localized, and are more readily identified. Typical examples of point sources include leaking underground storage tanks, sites contaminated through industrial activity, landfills, subsurface waste injection, mining activities, large-scale chemical spills which occur through road or rail accident and a myriad of lesser sources. An example of a lesser source is the careless disposal of old gasoline used for lawn mowers, etc. As small an amount as a single litre of gasoline can render 1 million L of water undrinkable.

In recent years, contaminated industrial sites and landfills have received much public attention. At many of these sites, groundwater becomes contaminated by way of dense non-aqueous phase liquids (DNAPLs). These are often mixtures of organic (and sometimes inorganic) compounds that do not mix well with water and have a density greater than water. Drycleaning solvents are a good example of a commonly found DNAPL. Clean-up of sites contaminated with DNAPLs has proven to be costly and ineffective. In Canada, sites contaminated by DNAPLs are only now being discovered and the cost to remediate these sites has yet to be estimated.

Groundwater contamination occurs when man-made products sucl as gasoline, oil, road salts and chemicals get into the groundwater and cause it to become unsafe and unfit for human use. Some of the major sources of these products, called contaminants, are storage tanks, septic systems, hazardous waste sites, landfills, and the widespread use of road salts, fertilizers. pesticides and other chemicals. 


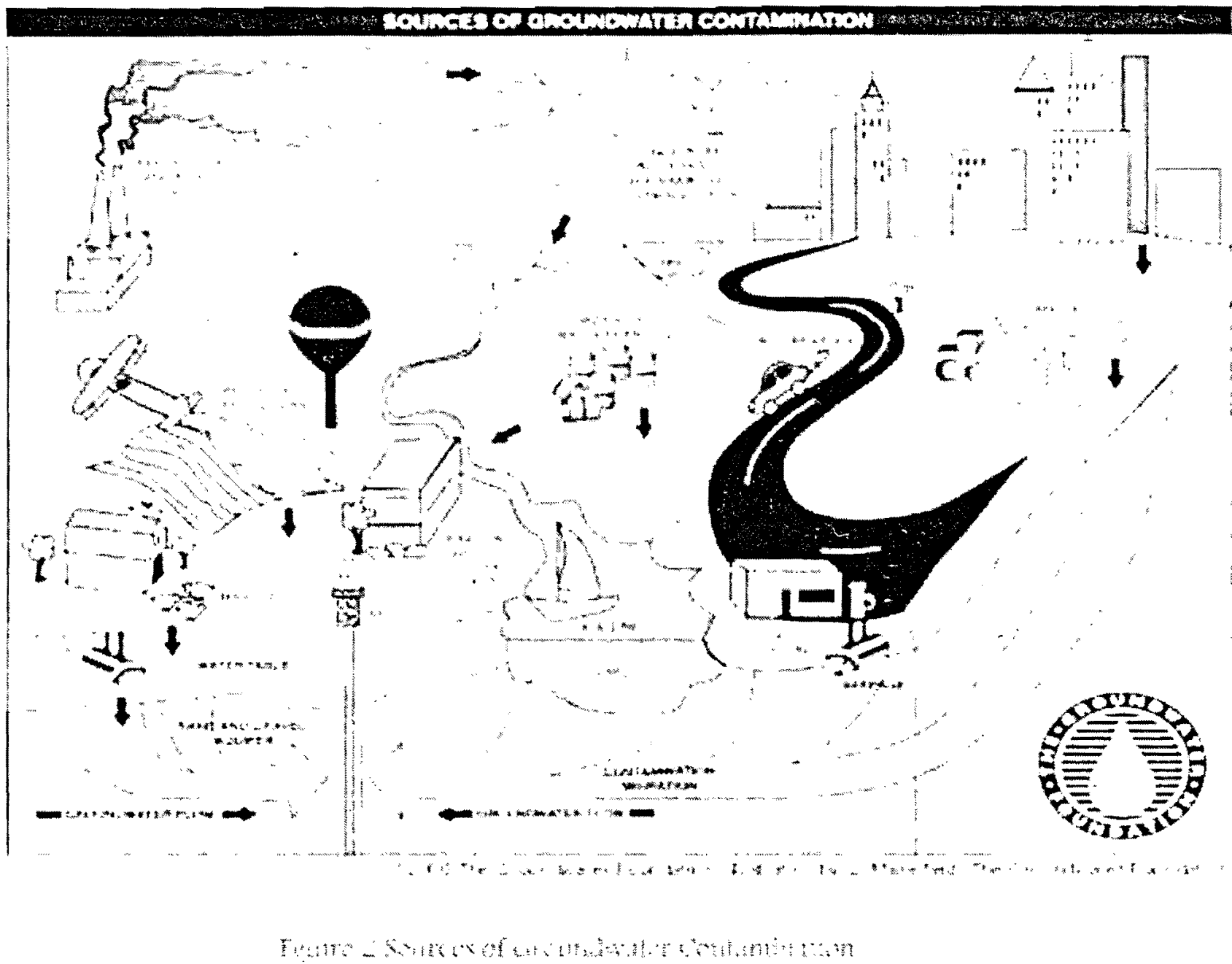

Storage tanks may contain gasoline, oil, chemicals, or other types of liquids and they can either be above or below ground. There are estimated to be over 10 million storage tanks buried in the United States and over time the tanks can corrode, crack and develop leaks. If the contaminants leak out and get into the groundwater, serious contamination can occur.

Septic systems can be another serious contamination source. Septic systems are used by homes, offices or other buildings that are not connected to a city sewer system. Septic systems are designed to slowly drain away human waste underground at a slow, harmless rate. An improperly designed, located, constructed, or maintained septic system can leak bacteria, viruses, houseliold chemicals, and other contaminants into the groundwater causing serious problems

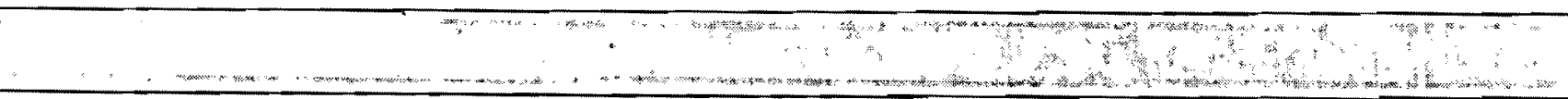




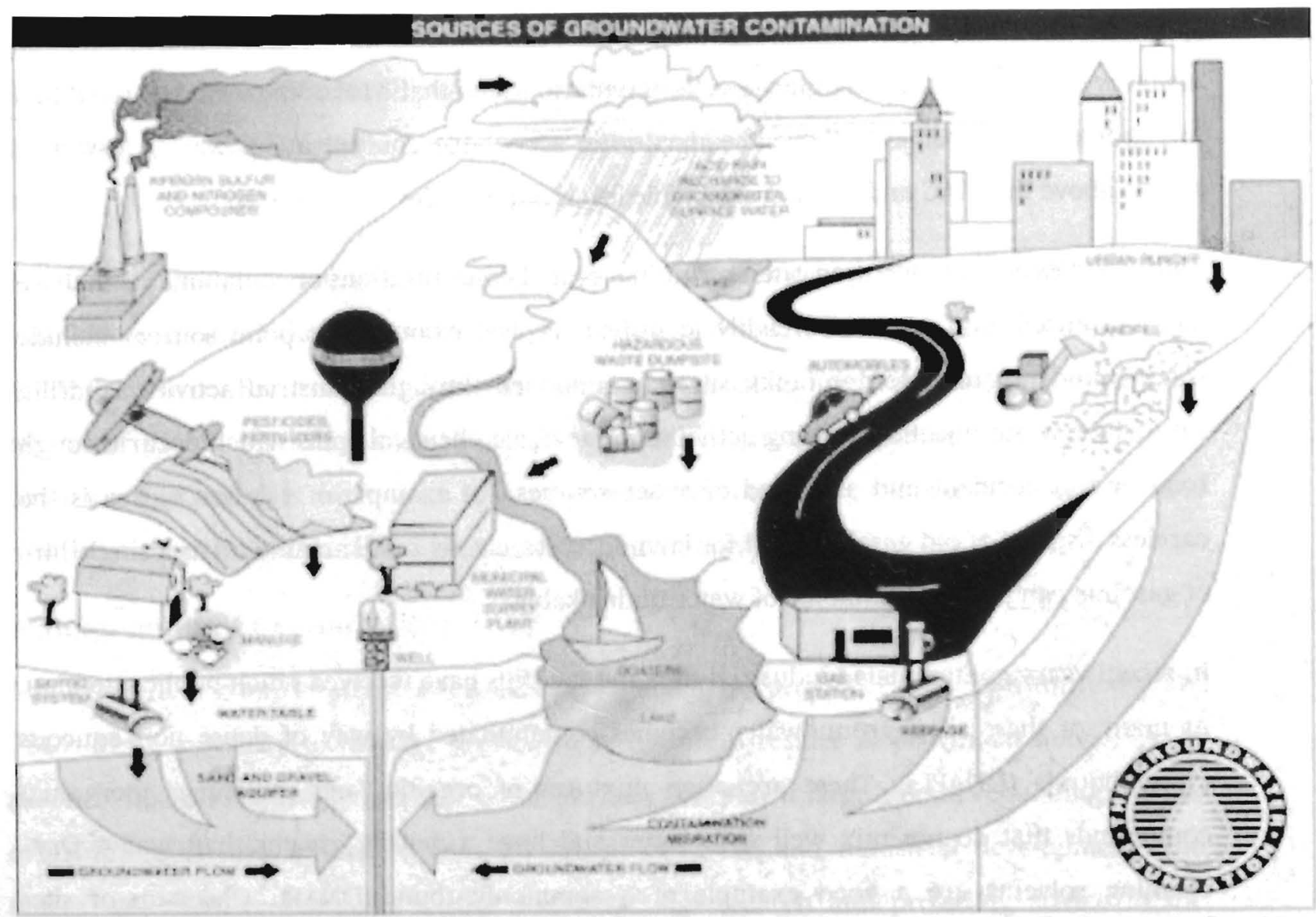

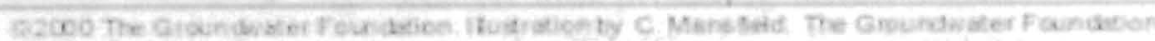

\section{Figure 2 Sources of Groundwater Contamination}

Storage tanks may contain gasoline, oil, chemicals, or other types of liquids and they can either be above or below ground. There are estimated to be over 10 million storage tanks buried in the United States and over time the tanks can corrode, crack and develop leaks. If the contaminants leak out and get into the groundwater, serious contamination can occur.

Septic systems can be another serious contamination source. Septic systems are used by homes, offices or other buildings that are not connected to a city sewer system. Septic systems are designed to slowly drain away human waste underground at a slow, harmless rate. An improperly designed, located, constructed, or maintained septic system can leak bacteria, viruses, household chemicals, and other contaminants into the groundwater causing serious problems 
In the United States today, there are thought to be over 20,000 known abandoned and uncontrolled hazardouş waste sites and the numbers grow every year. Hazardous waste sites can lead to groundwater contamination if there are barrels or other containers laying around that are full of hazardous materials. If there is a leak, these contaminants can eventually make their way down through the soil and into the groundwater.

Landfills are another major source of contamination. Landfills are the places that our garbage is taken to be buried. Landfills are supposed to have a protective bottom layer to prevent contaminants from getting into the water. However, if there is no layer or it is cracked. contaminants from the landfill (car battery acid, paint, household cleaners, etc.) can make their way down into the groundwater.

The widespread use of road salts and chemicals is another source of potential groundwater contamination. Road salts are used in the wintertime to put melt ice on roads to kecp cars from sliding around. When the ice melts, the salt gets washed off the roads and eventually ends up in the water. Chemicals include products used on lawns and farm fields to kill weeds and insects and to fertilize the plants. When the rain comes, these chemicals get washed into the ground and eventually into the water.

We have to remember that since groundwater is part of the hydrologic cycle, contaminants in other parts of the cycle, such as the atmosphere or bodies of surface water, can eventually be transferred into our groundwater supplics.

So now that you know the risks to groundwater, what can we do about it?

\section{Cinnd Water Remediation}

The discovery of hazardous wastes at Love Canal in Niagara, New York, and at numerous otlicr sites across the United States brought to light a new era in hazardous waste issucs and problems. During the hazardous waste decade of the 1980's, hydrologists, hydrogcologists, civil and envirommental engineers, and other scientists were involved in characterizing, cvaluatins, and remediating hazardous waste sites with respect to ground water contamination. The ficld of ground water has seen a virtual explosion in the number of remedial investigation sthatiss related to the thousands of abandoned and active hazardous waste disposal sitcs and loukins 
tanks across the United States. One of the main objectives of this text is to provide engincers and scientists with a modern treatment of remediation methods currently bcing practiced, but with an cye towards the future.

Emcrging new technologics are rapidly coming into place as we learn more about some of the failures of the past. Earlicr pump and treatment systems, which did not consider the presence of NAPLs is source zones, have not cleaned aquifers to the required levels. Many of the original systems worked adequately for a period of time, but after they were tumed off, many sites had contaminant levels retum to even higher values than before remediation. There have been success stories as well, with the discovery that many fuel (BTEX) plumes are limited in their extent due to natural attenuation processes. It is now widely recognized that EPA has given up the objectives of trying remediate shallow aquifers to drinking water standards. The actual use of these aquifers is now being considered in the overall evaluation of remedial options.

\section{Orevew}

This chapter has given a brief background to set the stage for the subsequent discussion of natural attenuation and defining the associated parameters. These parameters will be examined with the aid of BIOPLUME III, a two-dimensional model which will simulate the natural attenuation process in the saturated zone. Chapter 2 of the project consists of relevant literature on this topic. Chapter 3 talks about computer simulation. Clapter 4 includes the research design and the methodology employed for this research effort. Chapter 4 contains the data description and analysis and chapter 5 presents discussion of findings, conclusion.

Obioctives

\section{Goal of the Project.}

- Data Collection

Collecting data using studies done in the past

\section{- Design}

Selecting the right software to test the data

\section{- Simulation}

Using BIOPLUME III to run the simulations \& different scenarios 


\section{CHAPTER 2}

\section{LITERATURE REVIEW}

Carialul

\section{EVOLUTION OF GROUND WATER INFORMATION}

A number of classic textbooks in the ground water field have been written over the past thirty years. The field of ground water hydrology has expanded greatly since the first Amcrican textbook by Tolman (1937). Todd's (1959) text, Ground Water Hydrology, stood as a classic in the field for many years and was updated with a new edition in 1980 . DeWiest's text in 1965 and Davis and DeWiest in 1966 further advanced the subject with their books on geohydrology and hydrogeology. Bear's text written in 1972 and 1979 wcre departures from earlicr approaches and emphasized the hydraulics of ground water, providing a very theoretical development of flow and transport in both the saturated and unsaturated zonc of engineers, hydrologists, and hydrogeologists. In 1979. Frecze and Cherry's Ground Watcr quickly replaced others as the standard in the ground water field for more than a decade. Their chapters on transport, chemical properties, and contamination are still of great use even today. The book by Pankow and Cherry (1996) provides a modern and comprehensive coverage of DNAPLs and chlorinated solvents.

There has been an explosion of literature in the past two decades, and there are numerous new sources of information and data in the ground water hydrology area. The United States Geological Survey (USGS) has primary responsibility for the collection of ground water data and evaluation of these data in terms of impacts on water supply. water quality. water depletion, and potential contamination. Studies performed by engineering consultants for EPA and for industry during the remedial investigation or feasibility study of RCRA and Superfund sites also provide a useful description of applied methods in ground water. Other primary 
sources of information are state envirommental and water resources agencies, the American Geoplysical Union, and the National Ground Water Association. Joumals such as Water Resources Research, Ground Water, Joumal of Hydrology, the ASCE Journal of Environmental Engineering, and Environmental Science and Technology are major resources for exchange of information.

Srondus?

Mathematical models have been widely used to simulate fate and transport of the nonaqucous phase liquids (NAPLs) contaminants for risk assessment and remediation design studies (Chen et al., 1999). Rifai et al. (1987) developed a two-species bioremediation model, known as BIOFLUME-II, to predict fate and transport of hydrocarbon contaminants that degrade via aerobic reaction. The model was recently updated to describe other anaerobic reaction mechanism for modeling hydrocarbon decay processes. However, many theoretical and field studies have recognized that the contaminant fate in the subsurface is significantly influenced by uncertainties inherent in natural porous media and thus may affect model predictions (Gelhar, 1993). These uncertainties generally emerge from heterogeneity of hydrogeological enviromment and scarcity of related data, and they can further be related to aquifer characteristics and/or physical, chemical, and biological properties of the NAPLs being released and transported. Such property parameters can vary significantly from one site to another and also exhibit great spatial variability even within the same site. For example, hydraulic conductivity that spans orders of magnitude at the same site is not uncommon. Even with given the heterogeneity that exists in nature, it is simply not feasible to thoroughly define subsurface conditions at a given site. Attempting to do so would require an infinite number of borings, monitoring wells, sampling, and analyses; even if this work were done, the results would still be subject to nonunique interpretations (Adams, 1995). It is therefore essential that the fate and transport of NAPLs are simulated under parameter uncertainties, in order to provide robust information for enhancing performances of remediation actions.

In the past decades, the increasing awareness for uncertainties of porous media led to an improved understanding of contaminant transport behaviors in subsurface. It has been 
recognized that an optimal best-fit model calibration leading to a single averaged model prediction, even with some scnsitivity analysis, is of limited use and furthermore may suggest an unjustified and misleading degree of accuracy. A dcterministic model uscd for risk assessment and remediation design that underestimates uncertainty inherent in the subsurface might cause severe consequences such as damage to human health or property. Converscly, a site remediation system design based on a deterministic model that overestimates uncertainty would waste resources (Maqsood et al., 2003). Over the past years, various techniques wore advanced and employed to address the effects of parameter uncertainty through transport modeling, including first-order second-moment analysis, response surface methods, reliability analysis-based approaches, and fuzzy set-based approaches (Hammonds et al., 1994; Chang et al., 1995). For example, Kaluarachchi et al. (2000) developed a Lagrangian stochastic methodology for analyzing field-scale biodegradation of hydrocarbons in aquifcrs, using oxygen and nitrate as soluble electron acceptors. The subsurface hetcrogeneity was represented using a spatially correlated random hydraulic conductivity field with a log-normal distribution. Hu and Huang (2002) developed a nonlocal, first-order, Eulerian stochastic theory for studying reactive chemical transport in a heterogeneous, fractured porous medium under uncertainty. Li et al. (2003) proposed an integrated approach based on a modified fuzzy vertex method and applied it to the simulation of petroleum contamination in the subsurface. Maqsood (2004) developed an integrated fuzzy approach for quantifying relationships among uncertain hydrogeological parameters through techniques of fuzzy multi-attribute decision analysis and factorial design; furthermore, the health impacts from NAPLs contamination were also assessed.

The stochastic method has been used as a more realistic approach for evaluating uncertainties in groundwater flow and transport simulation systems in recent years (Gelhar, 1993; Mylopoulos et al., 1999; Zhu and Sykes, 2000). It may be generally classified as analytical or numerical. The first includes random parameters as coefficients in partial differential equations that describe the system to be modeled. Then the stochastic differential equations are solved. generally using spectral analysis to analyze perturbed forms of the equations. The second involves solving the governing equation using numerical methods based on the probability distributions of the imput parameters, among which the most popular approach so far is $M$ tonte 
Carlo simulation (Lahkim and Garcia, 1999). Such a method consists of iterative individual sampling to produce multiple simulation realizations and then analysis of all of the realizations to present the final output results (Chang et al., 1995; Lahkim and Garcia, 1999). The output realization is usually presented in the form of a probability distribution or a cumulative frequency distribution. Many applications with such approaches were reported in the field of subsurface flow and transport modeling during recent years (Clement et al., 2000; Zhu and Sykes, 2000; Mraqsood et al., 2003).

\section{Linitutions}

Bioremediation studies are data intensive and require detailed site characterization of the key parameters for biodegradation. In addition, in many cases, particularly when nutrients or microbial populations are introduced into the subsurface, it is required to know how these evolve in space and time. BIOPLUMEIII has not been updated since 1997. BIIOPLUMEIII is a two-dimensional model and cannot simulate problems in three-dimensions. 


\section{CHAPTER 3}

\section{COMPUTER SIMULATION}

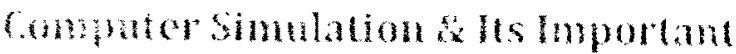

A computer simulation, a computer model, or a computational model is a computer program, or network of computers, that attempts to simulation/ simulate an abstract model (abstract) model of a particular system. Computer simulations have become a useful part of mathematical modeling of many natural systems in physics (computational physics), astrophysics, chemistry and biology, human systems in cconomics, psychology, social science, and engineering. Simulations can be used to explore and gain new insights into new techmology, and to estimate the performance of systems too complex for analytical solutions.

Computer simulations vary from computer programs that run a few minutes, to network-based groups of computers ruming for hours, to ongoing simulations that run for days. The scale of events being simulated by computer simulations has far exceeded anything possible or perhaps even imaginable using the traditional paper-and-pencil mathematical modeling: over 10 years ago, a desert-battle simulation, of one force invading another, involved the modeling of 66,239 lanks, trucks and other vehicles on simulated terrain around Kuwait, using multiple supercomputers in the United States Department of Defense /DoD High Performance Computer Modernization Program; a 1-billion-atom model of material deformation (2002); a 2.64 million-atom model of the complex maker of protein in all organisms, a ribosome, in 2005; : and the Blue Brain project at EPFL (Switzerland), began in May 2005, to create the first computer simulation of the entire human brain, right down to the molecular level

\section{Simulation versus Modeling}

Traditionally, forming large models of systems has been via a mathematical model, which attempts to find Analytic solution analytical solutions to problems and thereby enable the prediction of the behavior of the system from a set of parameters and initial conditions.

While conputer simulations might use some algorithms from purely mathematical models, computers can combine sinulations with reality or actual events. such as generating input 
responses, to simulate test subjects who are no longer present. Whereas the missing test subjects are being modeled/ simulated, the systcm they use could be the actual equipment. revealing performance limits or defects in long-term use by these simulated users.

Note that the tem "computer simulation" is broader than "computer modeling", which implies that all aspects are being modeled in the computer representation. However, computer simulation also includes generating inputs from simulated users to run actual computer software or equipment, with only part of the system being modeled, an example would be flight simulators which can run machincs as well as actual flight software.

Computer simulations are used in many fields, including science, technology, entertainment, licallh care, and business planning and scheduling.

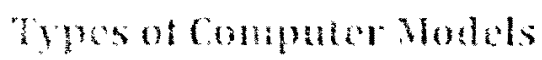

Computer models can be classificd according to several independent pairs of attributes. including:

- Stochastic or deterministic

- Stcady-state or dynamic

- Continuous or discrete

- Local or distributed.

Equations define the relationslups between clements of the modeled system and attempt to find a state in which the system is in equilibrium. Such models are often used in simulating physical systems, as a simpler modeling case before dynamic simulation is attempted.

- Dynamic simulations model changes in a system in response to (usually changing) input signals.

- Stochastic models use random number generators to model chance or random events;

- A discrete event simulation (DES) manages events in time. Most computer. logic-test and fault-tree simulations are of this type. In this type of simulation, the simulator maintains a queue of events sorted by the simulated time they should occur. The 
simulator reads the queue and triggers new events as cach cvent is processed. It is not important to exccute the simulation in real time. It's often more important to be able to access the data produced by the simulation, to discover logic defccts in the design, or the sequence of events.

- A continuous dymamic simulation performs numcrical solution of differential-algcbraic equations or differential equations (either partial or ordinary). Pcriodically, the simulation program solves all the equations, and uses the numbers to change the state and output of the simulation. Applications include flight simulators, construction and management simulation games, chemical process modeling, and simulations of electrical circuits. Originally, these kinds of simulations were actually implemented on analog computers, where the differential equations could be represented directly by various electrical components such as op-amps. By the late 1980s, however, most "analog" simulations were run on conventional digital computers that cmulate the bellavior of an analog computer.

- A special type of discrete simulation which does not rely on a model with an underlying equation, but can nonetheless be represented formally, is agent-based simulation. In agent-based simulation, the individual entities (such as molecules, cells, trces or consumers) in the model are represented directly (rather than by their density or concentration) and possess an internal state and set of behaviors or rules which determine how the agent's state is updated from one time-step to the next.

- Distributed models run on a network of interconnected computers, possibly through the Internet. Simulations dispersed across multiple host computers like this are often referred to as "distributed simulations". There are several standards for distributcd simulation, including Aggregate Level Simulation Protocol (ALSP), Distributed Interactive Simulation (DIS), the High Level Architecture (simulation) (HLA) and the Test and Training Enabling Architecture (TENA).

\section{Computer simulation in scicnce}

Generic examples of types of computer simulations in science, which are derived from an underlying mathematical description: 
- A numerical simulation of differential equations which cannot be solved analytically, theories which involve continuous systems such as phenomena in physical cosmology, fluid dynamics (e.g. climate models, roadway noise models, roadway air dispersion models), continuum mechanics and chenical kinetics fall into this category.

- A stochastic simulation, typically used for discrete systems where events occur probabilistically, and which cannot be described directly with differential equations (this is a discrete simulation in the above sense). Phenomena in this category include genetic drift, biochemical or gene regulatory networks with small numbers of molecules.

Specific examples of computer simulations follow:

- Statistical simulations based upon an agglomeration of a large number of input profiles, such as the forecasting of equilibrium temperature of receiving waters, allowing the gamut of metcorological data to be input for a specific locale. This technique was developed for thermal pollution forecasting.

- Agent based simulation has been used effectively in ecology, where it is often called individual based modeling and has been used in situations for which individual variability in the agents cannot be neglected, such as population dynamics of salmon and trout (most purely mathematical models assume all trout behave identically).

- Time stepped dynamic model. In hydrology there are several such hydrology transport models such as the SWMM and DSSAM Models developed by the U.S. Envirommental Protection Agency for river water quality forecasting.

- Computer simulations have also been used to formally model theories of human Cognition and performance, e.g. ACT-R

- Computer simulation using molecular modeling for drug discovery

- Computational fluid dynamics simulations are used to simulate the behaviour of flowing air, water and other fluids. There are one-, two- and three-dimensional models used. A one dimensional model might simulate the effects of water hammer in a pipe. A two-dimensional model might be used to simulate the drag forces on the cross-section 
of an acroplane wing. A three-dimensional simulation might estimate the heating and cooling requirements of a large building.

- An understanding of statistical thermodynamic molccular theory is fundamcntal to the appreciation of molecular solutions. Development of the Potential Distribution Theorcm (PDT) allows one to simplify this complex subject to down-to-carth prescntations of molecular theory.

Villls of Computersmulation

Although sometimes ignored in computer simulations, it is very important to perform sensitivity analysis to ensure that the accuracy of the results is properly understood. For example, the probabilistic risk analysis of factors determining the success of an oilficld exploration program involves combining samples from a varicly of statistical distributions using the Monte Carlo method. If, for instance, one of the key parameters (i.c. the net ratio of oil-bearing strata) is known to only one significant figure, then the result of the simulation might not be more precise than one significant figure, although it might (mislcadingly) be presented as having four significant figures.

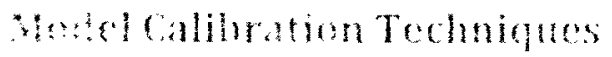

The following three steps should be used to produce accurate simulation models: calibration, verification, and validation. Computer simulations are good at portraying and comparing theoretical scenarios but in order to accurately model actual case studics, it has to match what is actually happening today. A base model should be created and calibrated so that it matches the area being studied. The calibrated model should then be verificd to ensure that the model is operating as expected based on the inputs. Once the model has been verificd, the final step is to validate the model by comparing the outputs to historical data from the study area. This can be done by using statistical techniques and cnsuring an adequate R-squared value. Lnless these techniques are employed, the simulation model created will produce inaccurate results and not be a useful prediction tool.

Model calibration is achieved by adjusting any available parameters in order to adjust how the model operates and simulates the process. For example in traffic simulation. typical parameters include look-ahead distance, car-following sensitivity, discharge headway, and start-up lost 
time. These parameters influence driver behaviours such as when and how long it takes a driver to change lanes, how much distance a driver leaves between itself and the car in front of it, and how quickly it starts to accelerate through an intersection. Adjusting these parametcrs las a direct effect on the amount of traffic volume that can traverse through the modeled roadway network by making the drivers more or less aggressive. These are examples of calibration parameters that can be fine-tuned to match up with characteristics observed in the field at the study location. Most traffic models will have typical default values but they may need to be adjusted to better match the driver behaviour at the location being studied.

Model verification is achieved by obtaining output data from the model and comparing it to what is expected from the input data. For example in traffic simulation, traffic volume can be verified to ensure that actual volume throughput in the model is reasonably close to traffic volumes input into the model. Ten percent is a typical threshold used in traffic simulation to determine if output volumes are reasonably close to imput volumes. Simulation models handle model inputs in different ways so traffic that enters the network, for example, may or may not reach its desired destination. Additionally, traffic that wants to enter the network may not be able to if any congestion exists. This is why model verification is a very important part of the modeling process.

The final step is to validate the model by comparing the results with what's expected bascd on historical data from the study area. Ideally, the model should produce similar results to what has happened historically. This is typically verified by nothing more than quoting the $\mathrm{R} 2$ statistic from the fit. This statistic measures the fraction of variability that is accounted for by the model. A high R2 value does not necessarily mean the model fifs the data well. Another tool used to validate modcls is graphical residual analysis. If model output values are drastically different than historical values, it probably means there's an error in the model. This is an important step to verify before using the model as a base to produce additional models for different scenarios to ensure each one is accurate. If the outputs do not reasonably match historic values during the validation process, the model should be reviewed and updated to produce results more in line with expectations. It is an iterative process that helps to produce more realistic models. 
Validating traffic simulation models requires comparing traffic estimated by the model to observed traffic on the roadway and transit systems. Initial comparisons are for trip interchanges between quadrants. scctors, or other large areas of interest. The next step is to compare traffic estimated by the models to traffic counts, including transit ridership, crossing contrived barriers in the study area. These are typically called screenlines, cutlines, and cordon lines and may be imaginary or actual physical barriers. Cordon lines surround particular areas such as the central business district or other major activity centers. Transit ridership estimates are commonly validated by comparing them to actual patronage crossing cordon lines around the central business district.

Three sources of error can cause weak correlation during calibration, input error, model error, and parameter error. In general, input error and parameter error can be adjusted easily by the user. Model error however is caused by the methodology used in the model and may not be as easy to fix. Simulation models are typically built using several different modeling theories that can produce conflicting results. Some models are more gencralized while others are more detailed. If model error occurs as a result of this, in may be necessary to adjust the model methodology to make results more consistent.

In order to produce good models that can be used to produce realistic results, these are the necessary steps that need to be taken in order to ensure that simulation models are functioning properly. Simulation models can be used as a tool to verify engineering theories but are only valid if calibrated properly. Once satisfactory estimates of the parameters for all models have been obtained, the models must be checked to assure that they adequately perform the functions for which they are intended. The validation process establishes the credibility of the model by demonstrating its ability to replicate actual traffic patterns. The importance of model validation underscores the need for careful planning, thoroughness and accuracy of the input data collection program that has this purpose. Efforts should be made to ensure collected data is consistent with expected values. For example in traffic analysis, it is typically common for a traffic engincer to perform a site visit to verify traffic counts and become familiar with traffic patterns in the area. The resulting models and forecasts will be no better than the data used for model estimation and validation. (Wikipedia) 


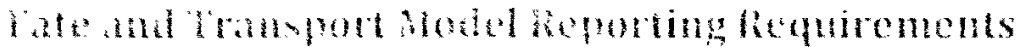

When a site has low levels of contamination, it may be feasible to allow the regulated substances to naturally attenuate as opposed to an active remediation method. In order to approve monitored natural attenuation, the responsible parties must demonstrate that the site is likcly to reach clean-up standards within a reasonable time. One of the requirements for this demonstration is a fate and transport model.

The model may be either analytical or numerical and should include a report with sufficient detail that the reviewer would be able to duplicate the model. In order to assure that the model has ben through an acceptable peer review, the model must also be associated with the EPA, either approved in an EPA document, written by the EPA, or some other disclosed association.

\section{A fate and transport model report should include the following:}

- Description of the model, how it approaches the problem, and its limitations, showing that the model is appropriate for use at the site.

- Description of the model association with the EPA.

- Summary of current site contamination.

- Most recent potentiometric surface map for the site.

- Model input values in tabular form including:

- Field measurements

- Calculations

- References or explanation of input values

- Examples of all calculations.

- Modcl calibration procedures. 
- Scnsitive parameters for model, any sensitivity analysis showing range of acceptable model adjustments, and rational for selecting input values for sensitive parameters.

- Model output showing range of results.

- If simple calculation model used, output data should be presented in tabular form.

- If computer model used, output data should be presented in both tabular form and a printout of the output pages should be provided.

- A series of maps showing reduction of regulated substances over time.

- Maps must show reference points (monitoring wells, targets, and significant landmarks).

- Maximum 5-year span between map.

- Other figures, tables, or discussions may be required depending on the complexity of the model and/or the site.

- Model results

- Statement of how many years for site to come into compliance with applicable risk reduction standards.

\section{Common Modeling Errors.}

- Units are inconsistent (For example, using standard and metric units without converting).

- Insufficient field data for calibration.

- Insufficient boundary size and/or conditions.

- Inaccurate hydrologic assumptions. 
- Incorrect sign for pumping or recharge.

- Typos or general mistakes in input values.

- Using input data that doesn't match the site.

- Excluding data from wells with the highest contamination.

- Improper selection and use of source and target wells.

- Target wells clustered in only small portion of the model.

- Incorrect assumptions regarding the effect of soil/source removal on source area groundwater contamination (Example, assume 50\% contamination loss in source well due to removal of overlying soil).

- Forcing data to fit using maximum or minimum ranges of input values.

- Acceptance of model output without logical assessment.

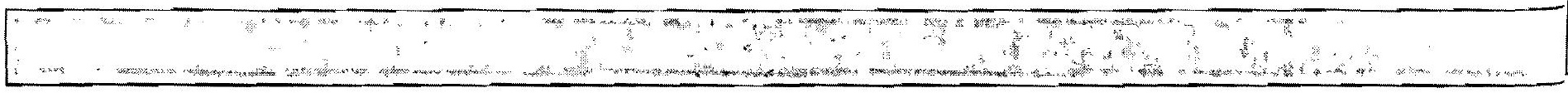




\section{CHAPTER 4}

\section{METHODOLOGY}

\section{Shandation hudel}

BIOPLUME III is a numerical two-dimensional (2D) model that tracks the fate and transport of aromatic hydrocarbons. The user inputs 2D contour maps of hydrologic parameters such as hydraulic head and hydraulic conductivity using a digitizing tool. Maps of initial concentrations of petroleum constituents and electron acceptors are input in the same manner. The model then calculates concentration contours at user-specified time intervals, using either an "instantancous reaction" model based on stoichiometry, or a first-order kinetic model.

\section{EPA version of popular 2D flow/transport/aerobic biodegradation model}

BIOPLUME III is a 2D, finite difference model for simulating the natural attenuation of organic contaminants in ground-water due to the processes of advection, dispersion, sorption, and biodegradation. Biotransformation processes are potentially important in the restoration of aquifers contaminated with organic pollutants. As a result, these processes require evaluation in remedial action planning studies associated with hydrocarbon contaminants.

It is based on the USGS solute transport code MOC and solves the solute transport equation six times to determine the fate and transport of the hydrocarbons and the electron acceptors $(\mathrm{O} 2$, $\mathrm{NO}_{-}, \mathrm{Fe} 3+, \mathrm{SO} 42-$ and $\mathrm{CO} 2$ ) and the reaction by-products $(\mathrm{Fe} 2+)$. A number of acrobic and anaerobic electron acceptors such as oxygen, nitrate, sulfate, iron (III) and carbon dioxide have been considered in this model to simulate the biodegradation of organic contaminants.

Three different kinetic expressions can be used to simulate the aerobic and anaerobic biodegradation reactions. These include: first-order decay, instantaneous reaction and Monod kinetics. The principal of superposition is used to combine the hydrocarbon plume with the electron acceptor plumes. The model has been integrated with a sophisticated ground-water modeling platform known as EIS. A graphical user platform allows the user to create, enter and edit data for model simulation. Discretization of time and space, hydrogeologic characteristics 
of the aquifer, initial and boundary conditions, sources and sinks, sorption, source decay, radioactive decay, ion-exchange and biodegradation variables are the different input paramcters of the model.

The model gencrates a standard output file that lists the results from a specific model rum. This output file lists the input data for the run followed by computed head and concentration maps. Simulation results are also shown graphically. Data can be cxtracted and used in conjunction with a graplics generation software program to generate graphical results from the model.

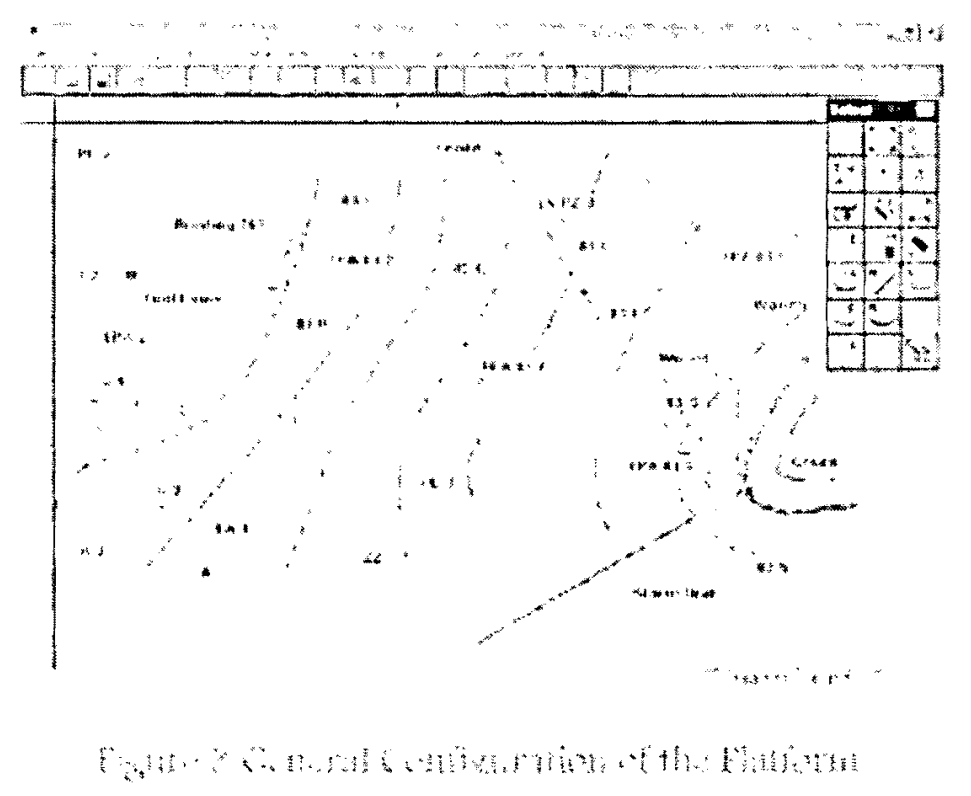

Ohlinm Mullous

- Finite Difference

- Finite Volume

Ind lions

- Numerical Modeling

- Visualization

- Remedial Process Selcction 
of the aquifer, initial and boundary conditions, sources and sinks, sorption, source decay, radioactive decay, ion-exchange and biodegradation variables are the different input parameters of the model.

The model generates a standard output file that lists the results from a specific model run. This output file lists the input data for the run followed by computed head and concentration maps. Simulation results are also shown graphically. Data can be extracted and used in conjunction with a graphics generation software program to generate graphical results from the model

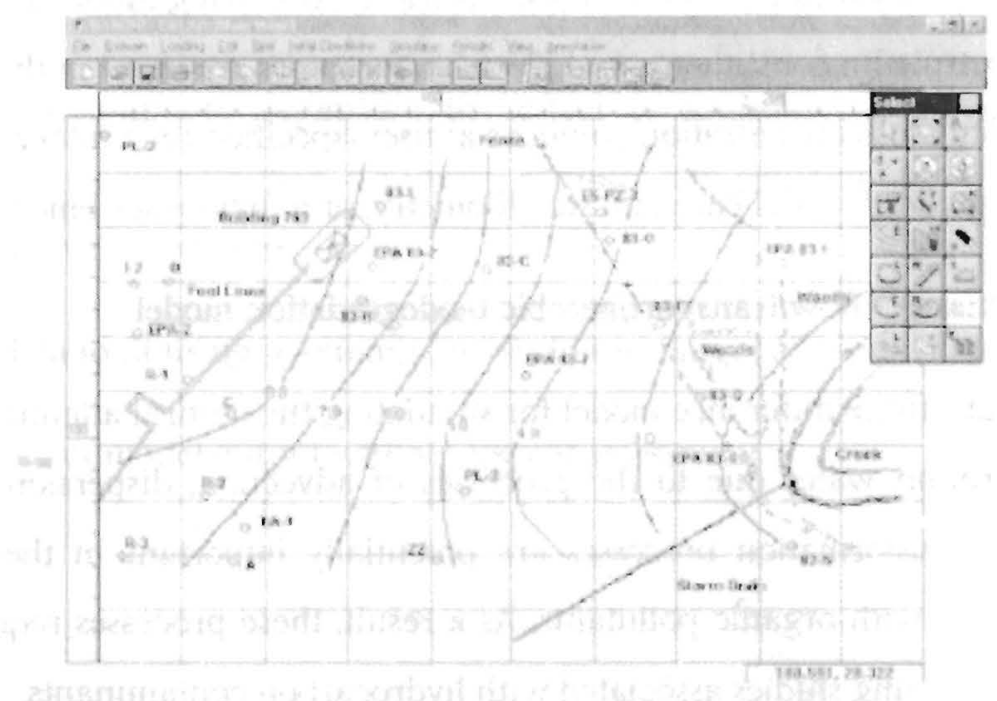

Figure 3 General Configuration of the Platform.

\section{Solution Methods}

- Finite Difference

- Finite Volume

\section{Functions}

\section{- Numerical Modeling}

- Visualization

- Remedial Process Selection 
SIOPLUMEIII-Data Loading

- Model input values are entered manually and digitized within the program.

\section{Biodegradation Election Acceplors}

Select Electron Acceptors and Set Parameters

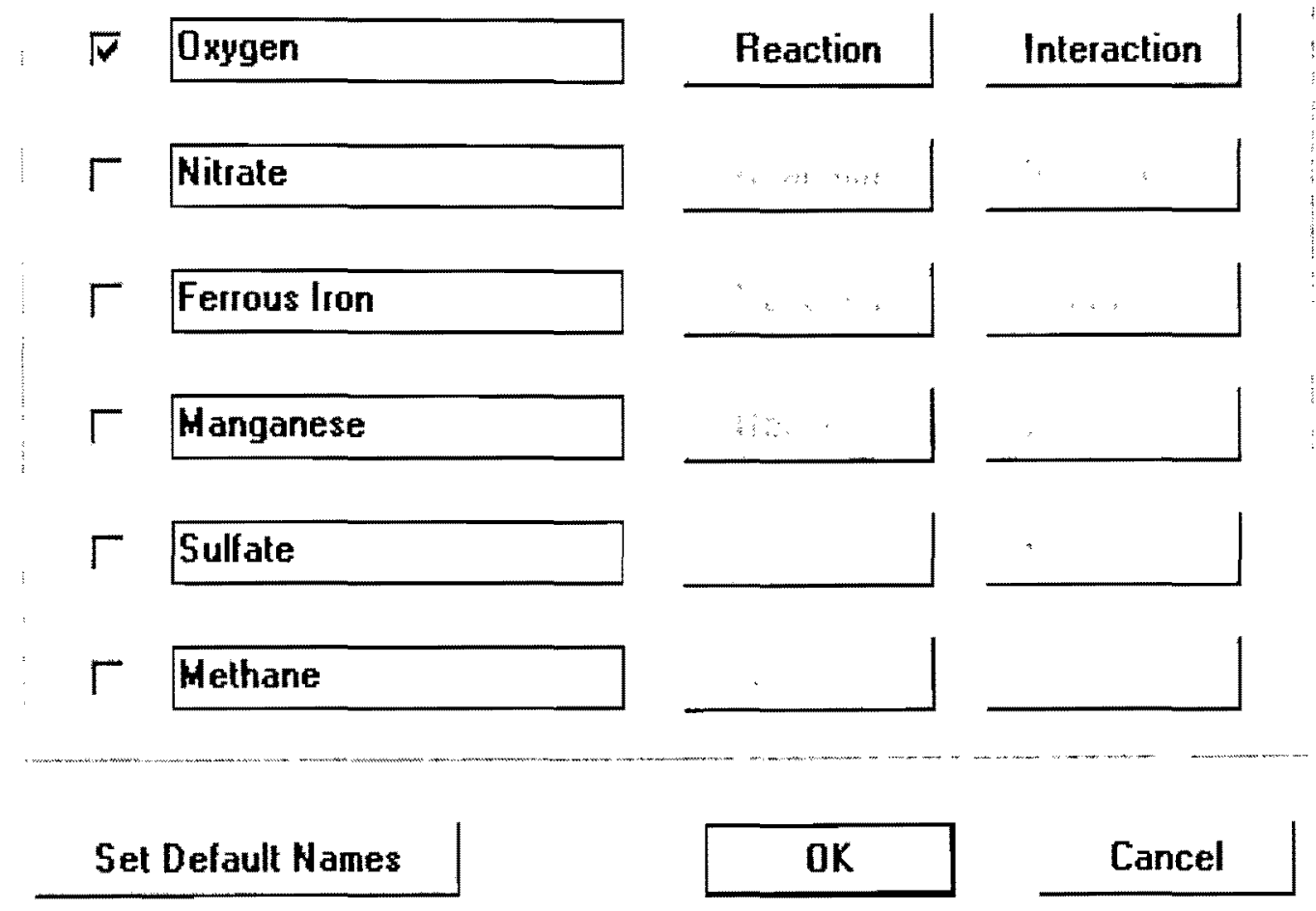

1. 


\section{BIOPLUME III- Data Loading}

- Model input values are entered manually and digitized within the program.

\section{Biodegradation Electron Acceptors}

Select Electron Acceptors and Set Parameters

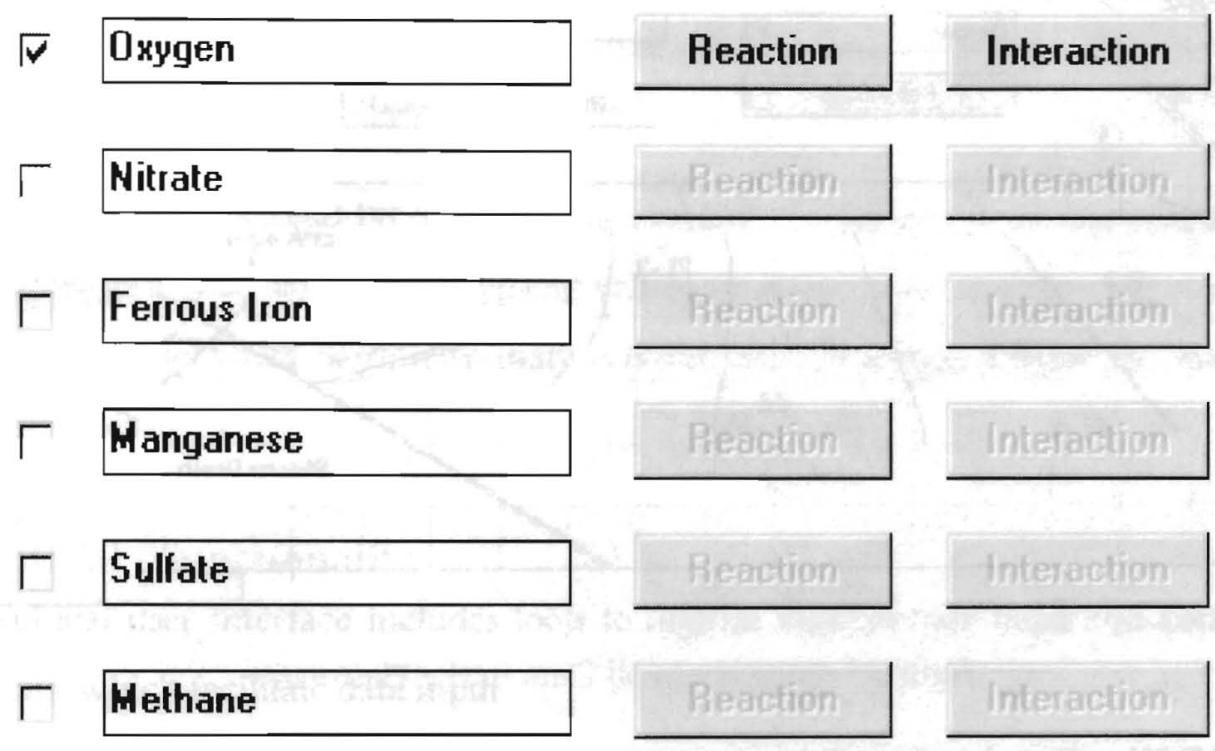

Set Default Names

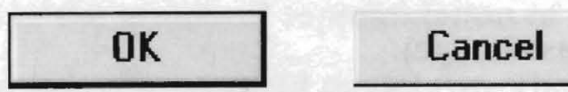

Figure 4. Platform confrols to imput water quality data. 
.

$=|0| x \mid$

File Domain Loadng Edi Gind Inital Conditons Smatator Fesuls View Annotation

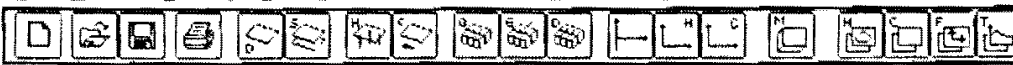

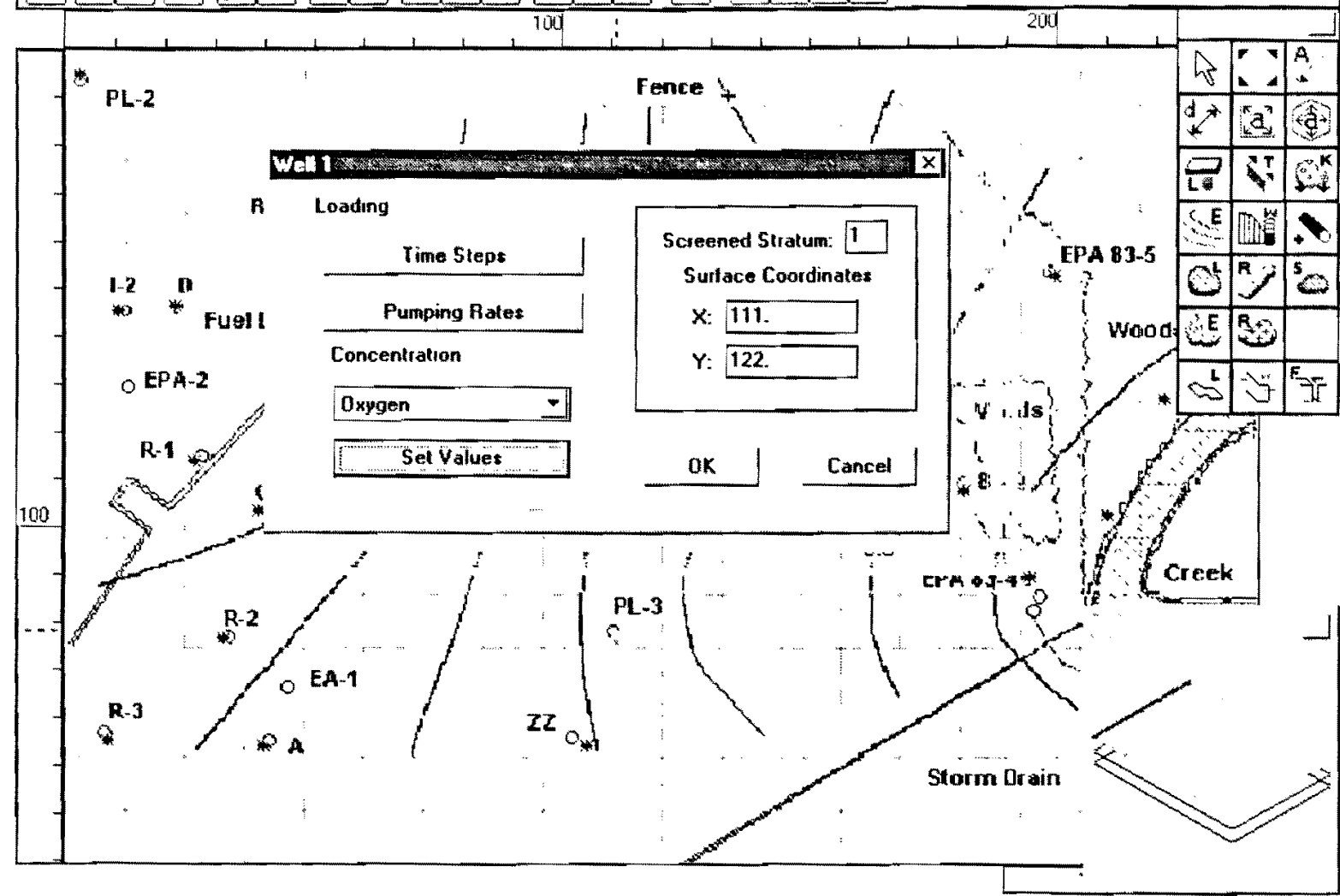

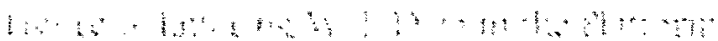

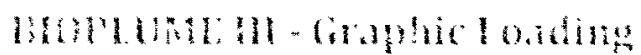

- Basc maps can be loaded to the model in a bitmap (bmp) file format in the Domain menu (Domain:Base Image).

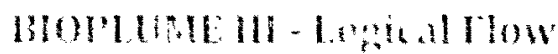

- Menus along the top of screen are arranged to follow logical flow from left to right. Some buttons are grayed out until the uscr completes the necessary precursor steps. 


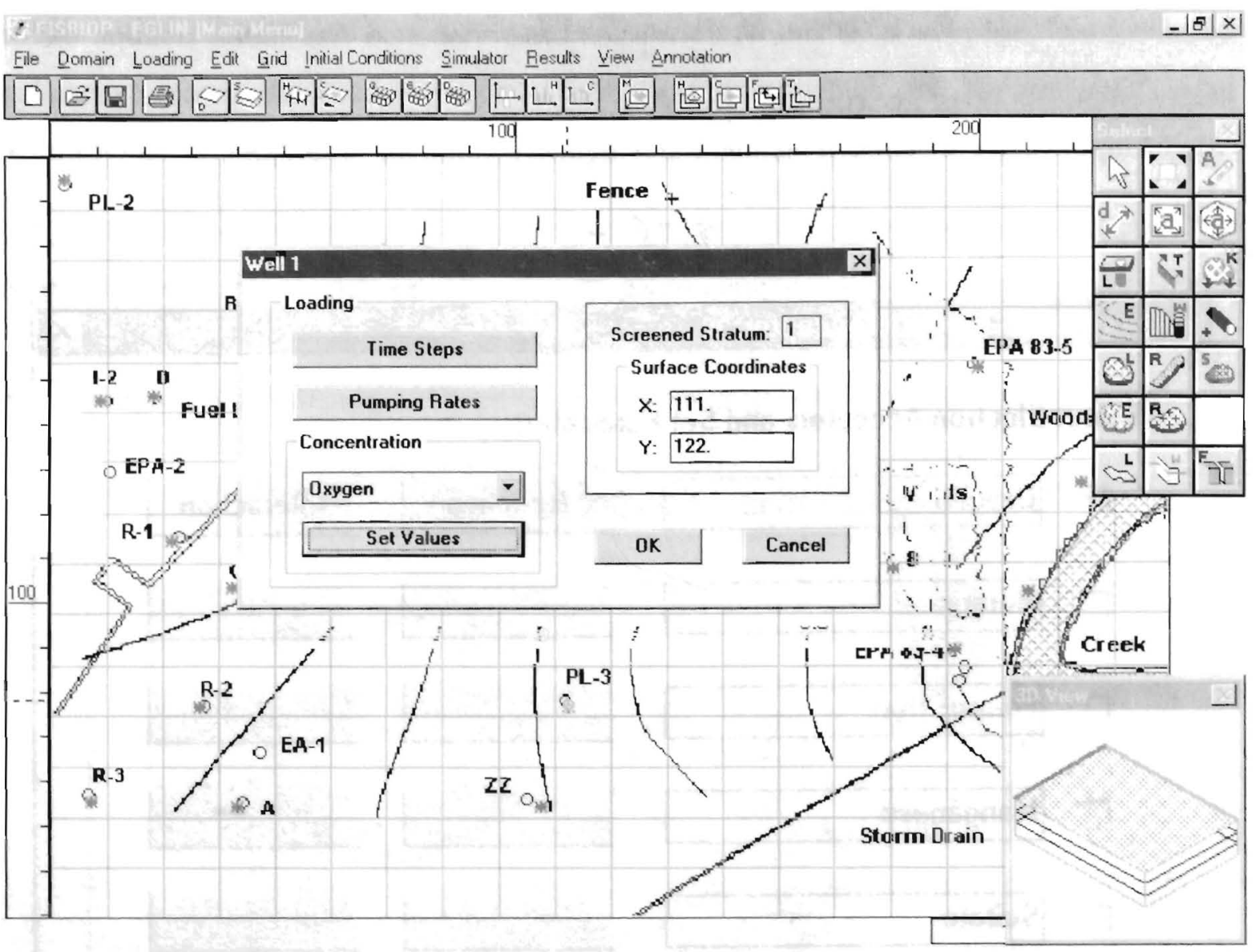

\section{Figure 5 Entering Well Dafa in the Platform}

\section{BIOPLUME III - Graphic Loading}

- Base maps can be loaded to the model in a bitmap (bmp) file format in the Domain menu (Domain:Base Image).

\section{BIOPLUME III - Logical Flow}

- Menus along the top of screen are arranged to follow logical flow from left to right. Some buttons are grayed out until the user completes the necessary precursor steps. 


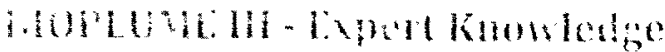

- Site-specific data should be used whenever possible to estimate model parameters so that the model is representative of potential site conditions. Although site-specific data are always preferred. "typical" ranges of many of the input parameters are provided in Appendix I of the manual. The selcction of "typical" parameters should be reviewed by the appropriate expert (liydrogeologist, chemist, or envirommental engineer).

- The user should have some expericnce in reading and understanding numerical model output filles, such as are commonly used in FORTRAN-based groundwater flow and transport models. Model output files should be analyzed after significant changes have been made or whenever the motel results require troubleshooting.

- A sensitivity analysis should be conducted to evaluate the sensitivity of model results to the inptit parameters, particularly when "typical" values are used rather than parameters estimated from site-specific field data. Sensitivity analysis is discussed in Section 4.3 .2 of the manual.

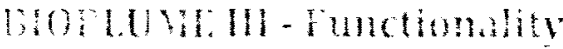

- The graplical user interface includes tools to digitize and contour head and concentration distributions, which facilitate data input.

- The user can animate the model results by clicking "AVT animation" under the Results menu to produce a video clip. The video clip is composed of the graphical representation of the plume or the piezometric surface at the end of each time step of a transient model run. The video clip can be shared with any stakeholders; Windows MediaPlayer or similar software is required to view the clip.

- The user must print the model report (File; Report) to troubleshoot or analyze model results. The model report may consist of 50 to 100 pages of output, so the computer should be connected to a printer. Output files are similar in format to raw Method of Characteristics $(M 10 C)$ files. 
- Complex scenarios will cause BIOPLUME III to crash. User experience suggests that a large grid (more than 50 rows by 50 columns) or a model with more than 10 to 15 pumping wells may crash the model run.

- A new version of BIOPLUME (BIOPLUME IV) is in beta-testing and should be available soon. The new version is reported to accept a $100 \times 100$ grid without crashing.

- Error messages are unclear to general technical staff and may require a trained FORTRAN programmer to decipher them.

\section{BIOPLUME III - Technical Application}

- BIOPLUME III is well-suited to model remediation scenarios that involve monitored natural attenuation (MNA) and pump-and-treat, with associated components such as source removal, injection of oxygenated water, or infiltration of oxygenated water. It is not well-suited to accurately represent the effects of air sparging.

- Although BIOPLUME III appears to be designed primarily for benzene, toluene, ethylbenzene, and xylene (BTEX) plumes (all discussions in the manual of specific contaminants refer to BTEX constituents), it has been successfully applied to chlorinated solvent sites (EPA 2001).

- BIOPLUME is generally used to predict changes to chemical concentratrions and hydraulic heads assuming simplified aquifer geometry, stresses and boundary conditions. Detailed hydrogeological studies require the calibration of a flow model using a high resolution, threedimensional model such as MODFLOW or FEMWATER.

\section{BIOPLUME III - Documentation}

- Users manual has clear layout, including sections on "Getting Started/Tutorial," "Theoretical Development," "User's Guide." and several appendices.

- Appendices provide useful information that should be reviewed before BIOPLUME III is used. Appendix I provides information on input data parameters. Appendix II discusses how to 


\section{Advantages}

To help the environmental professional with the data management, visualization, and decision making tasks involved, Bioplume III adopted the EIS Graphical User Interface Platform. EIS (Environmental Information System) is an integrated software platform under Windows 95 in which to register, sort, and evaluate the site-specific data of the physical processes influencing the groundwater migration of organic contaminants. The EIS platform permits integration and quantification of the simulation and data processing error to the risk of health hazard. BIOPLUME III is available for free from the EPA Center for Subsurface Modeling support web site - http//www.cpa.gov/ada/csmos/models.html 
interpret output files. The user will need to refer to these appendices for help in interpreting and troubleshooting model results.

- Appendix A provides detailed information on the Method of Characteristics (MOC) particle tracking code that BIOPLUME III is built around.

- Appendix B is a concise discussion of the U.S. Air Force intrinsic remediation (natural attenuation) protocol and describes implementation of BIOPLUME III in the broader context of . a natural attenuation study.

- There are no Help menus.

\section{BIOPLUME III - Output}

- Some graphics can be exported in a bitmap (bmp) format from the Results menu after a model run, specifically the head distribution and any concentration distribution. The user clicks on the Bitmap Capture button in the lower left of the toolbox to save the image to a bitmap. Output cannot be saved to a vector format.

- Model-estimated values of concentration or hydraulic head can be exported using the Spyglass tool in the upper left-hand corner of the Results toolbox (the toolbox that is active when the user is in the Results menu). The user can delineate an area of the grid to export results by clicking the tool and then dragging the cursor over the grid.

\section{BIOPLUME III - Sources}

- Version 1.0 (September 1997) downloaded December 14, 2004.

- Users Manual (EPA/600/R-98/010).

- EPA. 2001. Evaluation of the Protocol for Natural Attenuation of Chlorinated Solvents. Case Study at the Twin Cities Army Ammunition Plant. EPA Office of Research and Development. EPA/600/R-01/025. March 


\section{CHAPTER 5}

\section{RESULTS \& ANALYSIS}

\section{Case Study 1}

Evaluation of Natural Attenuation of Chlorinated Solvents in Ground Water.

OVERVIEW AND GOAL OF STUDY (the Twin Cities Army Ammunition Plant - Site A)

Past disposal of solvents in the soils at Site $A$ at the Twin Cities Army Ammunition Plant (TCAAP) resulted in the contamination of the shallow aquifer with perchlorocthylene and trichloroetlyylene, in addition to other contaminants. Contaminated ground water moved in a nortliwesterly direction from the contaminant sources toward private wells of residences just north of the TCAAP boundary. Remediation efforts have included soil excavation and the placement of pumping wells intended to prevent further migration of contaminated groundwater.

The long-term fate of the ground water plume is still in question. The presence of the cisisomer of dichloroethylene demonstrates that perchloroethylene is biologically degrading through reductive dehalogenation at the site. This is important because natural attenuation studies at other sites have demonstrated that natural attenuation (which includes biological degradation) is a large factor in the extent of ground water contamination and the time to ground water restoration. The goal of this study was to assess how natural attenuation has influenced the development of the ground water plume at Site $A$ and its role in the eventual restoration of the aquifer. 


\section{Background}

\section{Natural Attenuation}

Laboratory and field research have demonstrated that chlorinated solvents are biodegradable under certain environmental conditions. However, unlike the monoaromatic hydrocarbons benzene, toluene, ethylbenzene, and xylenes (BTEX) that biologically degrade acrobically, chlorinated solvents such as perchloroethylene (PCE) or trichloroethylene (TCE) degrade optimally under strongly reducing conditions. The reductive dehalogenation may be rapid under sulfate reducing or methanogenic conditions in ground water. Demonstrating that the ground water environment is favorable to reductive dehalogenation processes is therefore important in an assessment of natural attenuation at a site and the long term fate of a contaminant plume. In addition, the metabolites of TCE or PCE degradation, cis dichloroethylene ( $\mathrm{CDCE}$ ) and vinyl chloride (VC), may break down under iron reducing or manganese reducing conditions in addition to sulfate reducing or methanogenic conditions. Hydrogen concentration in ground water is correlated to the geochemistry at the site, and is a useful indicator of the potential for reductive dehalogenation.

The combined effect of dispersion, sorption, and biological degradation on ground water contaminants can be quantified in terms of the natural attenuation capacity at the site. This capacity may be large enough to contain the contamination within regulatory boundaries and contribute substantially to the collapse of the plume and restoration of the ground water. Simulating the effect of natural attenuation on the contaminants using computer models can assist in evaluating plume development and lead to cost-effective remediation decisions. 
Aerobic

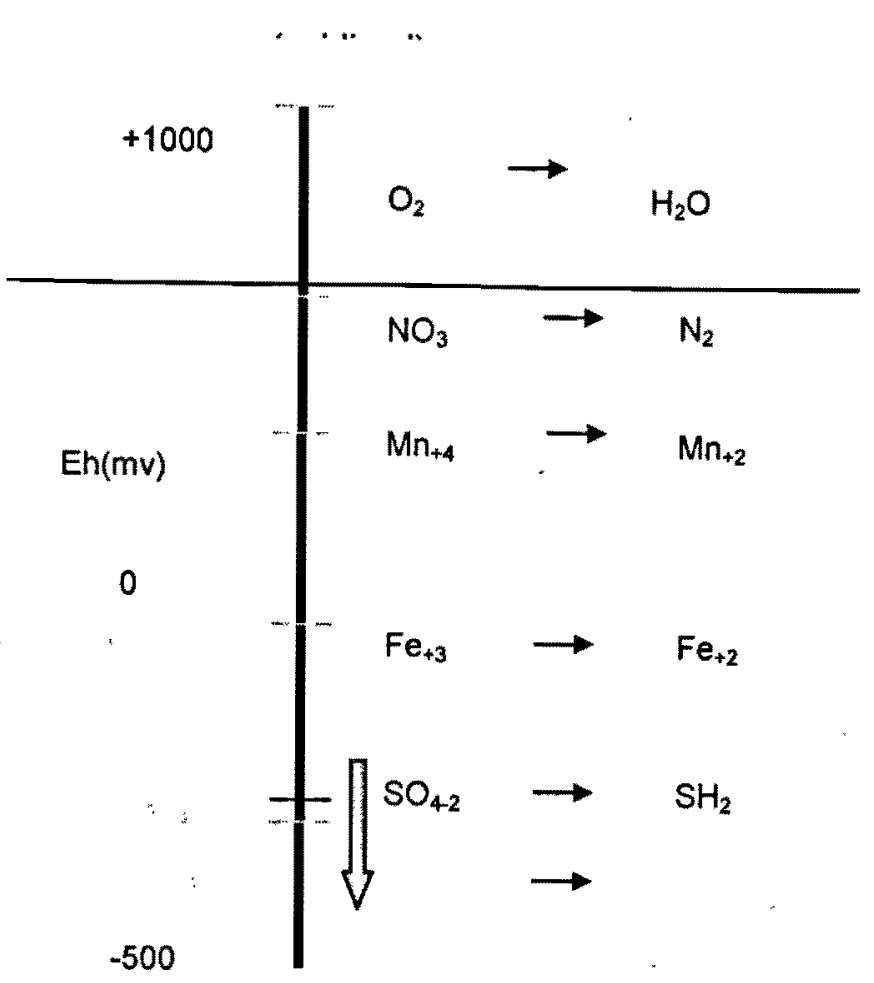

Anaerobic

(reduced)

Figure 6 Reductive dehalogenation of chlorinated solvents is most favorable under sulfate or carbon dioxide reducing conditions, indicated by the arrow 


\section{Site $A$ History and Description}

Site $A$ is located on the north end of TCAAP (Figure 7). The water table is 15 to 19 feet below ground surface, with the Unit 1 aquifer ranging in thickness from 15 feet near the source area to 28 feet to the west. The soils consist of loamy, fine sands with layers of iron oxide rich zones. The Unit 1 aquifer sediments are composed of lacustrine silt and fine or medium sands. This is underlain by the Twin Cities Till (Unit 2) which, due to its high clay content, serves as an effective aquitard to the Unit 1 aquifer. Unit 2 is approximately 12 to 88 feet thick at Site A. Ground water flows in a northwesterly direction toward Rice Creek with a horizontal hydraulic gradient in the area ranging from 0.0025 to $0.005 \mathrm{ft} / \mathrm{ft}$.

Estimation of aquifer parameters such as hydraulic conductivity, hydraulic gradient and hydrodynamic dispersion are important factors effecting transport.

Hydraulic Contuctivity is a measure of an aquifer's to transmit water and is perhaps the single most important aquifer parameter governing fluid flow in the subsurface. The velocity of groundwater and dissolved phase contaminants is directly related to the hydraulic conductivity of the saturated zone. In addition, subsurface varations in hydraulic conductivity directly influence contaminant fate and transport by providing preferential pathways for contaminant migration. The most common methods used to quantify hydraulic conductivity in the subsurface are aquifer pumping tests and slug tests

Hydraulic Gradient is the change in hydraulic head (feet of water) divided by the length of ground water flow. To accurately determine the hydraulic gradient, it is necessary to measure ground water levels in all monitoring wells at the site. Because hydraulic gradient can change over a short distance within the aquifer, it is essential to have as much site-specific ground water elevation information as possible so that accurate hydraulic gradient calculations can be made. In addition, seasonal variations in ground water flow directions can have a profound influence on contaminant transport. To determine the effect of seasonal variations in ground water flow direction on contaminant transport, quarterly ground water level measurement should be taken over a period of at least one year. 
Sensitivity analysis was done to analyze the influence of permeability on simulation results, and found that the influence is rather slight in the case study.

Assuming an aquifer thickness of 17 feet at the site. IT Corp. estimated in 1988 that the ground water hydraulic conductivity for Unit 1 was $8.3 \times 10-3 \mathrm{~cm} \mathrm{sec}-1$ ( $8.59 \times 103 \mathrm{ft} \mathrm{yr}-1)$. Using a gradient of 0.005 and a porosity of 0.2 , ground water velocity is estimated at 200 feet per year at Site A. Although it is unknown when solvents were disposed at the site, aerial photographs suggest that trenches and pits were used at the site for waste in the early 1940s, shortly after TCAAP was constructed. Historical ground water data appear to indicate the presence of multiple sources at the site but are difficult to define and fully delineate; however, the ground water contaminant concentrations at monitoring well $01 \mathrm{U} 108$ are the highest detected at the site historically. Thus, for the purposes of this study, the area near well 010108 is generally considered the primary source of chlorinated solvents to the Unit 1 aquifer.

The ground water investigation at the site began in 1983. The primary concern was for the residences with private wells to the north and northwest of the site that were in the path of the contaminant plume (Figure 4). Subsequent sampling of these wells showed that TCE and CDCE were present in some of these wells, though none of the contaminants were detected above Minnesota Health Risk Limits (HRLs). No PCE was found in these residential wells. The highest concentrations of CDCE at monitoring wells 01 U902 and 01 U904 situated on the north side of County Road I were roughly $100 \mu \mathrm{g} / \mathrm{L}$ in the early 1990s, with concentrations of TCE at 2 to 3 $\mu g / \mathrm{L}$. At monitoring well 01U108, PCE concentrations exceeded $1000 \mu g / \mathrm{L}$ in 1985, with TCE and DCE concentrations over $500 \mu \mathrm{g} / \mathrm{L}$ from 1985-1990. Attachment A contains plume maps from 1991, 1992, 1995, 1996, 1997, and 1999 showing the approximate spatial distributions. of $\mathrm{CDCE}$. TCE, and PCE in ground water at the site. In addition, plots of PCE, TCE, and CDCE concentrations as a function of time are also included for monitoring wells 01U108, 01U117. 01U115, 01U902, and 01U904. Prior to 1999, contour maps show the plume consisting of two lobes, one emanating from the area of monitoring well 010108 and one from the area of monitoring well 01U102, to the west of well 01U108. This conceptual understanding of the plume changed with analysis in the 1999 Annual Performance Report, when it was discovered that monitoring well $01 \mathrm{U} 125$ was screened at the water table. As a result, water from this well 
did not contain the contaminants of wells with larger well screens and was therefore unrepresentative of ground water contamination in this area. The ground water contamination is now configured as one large plume, and not two as reported previously.

In September of 1988, extraction well 350 was installed near monitoring well 01 U108 as part of an interim response action intended to remove and treat the high concentrations of contaminants found at this location. Well 350 operated at 4 gallons per minute (gpm). Pumping at this well was stopped in 1994 based on an evaluation of its effectiveness. In 1994. eight additional extraction wells were installed downgradient of the source area (Figure 5) intended to prevent contaminants from migrating further downgradient with a combined pumping rate of approximately $30 \mathrm{spm}$

Table 1 Part of modeling input parameters

\begin{tabular}{|l|c|c|c|}
\hline & & & \\
\hline
\end{tabular}




\begin{tabular}{|c|c|c|}
\hline NAPL/water interfacial tension & 45 & Dynes/cm \\
\hline NAPL density & 0.713 & $\mathrm{~g} / \mathrm{cm}^{3}$ \\
\hline Longitudinal dispersivity of sandy soil & 5 & m \\
\hline Longitudinal dispersivity of clay till & 5 & $\mathrm{~m}$ \\
\hline Longitudinal dispersivity of silty clay & 5 & m \\
\hline Transverse dispersivity of sandy soil & 0.5 & $\mathbf{m}$ \\
\hline Transverse dispersivity of clay till & 0.5 & $\mathbf{m}$ \\
\hline Transverse dispersivity of silty clay & 0.5 & $\mathrm{~m}$ \\
\hline Hydraulic gradient & 0.005 & $\mathrm{~m} / \mathrm{m}$ \\
\hline NAPL/water partition coefficient of benzene & 0.00203 & \\
\hline NAPL/water partition coefficient of E-benzene & 0.000173 & \\
\hline NAPL/water partition coefficient of toluene & 0.000594 & \\
\hline NAPL/water partition coefficient of xylenes & 0.000175 & \\
\hline Benzene solubility & 1750 & ing/1 \\
\hline Ethylbenzene solubility & 152 & $\mathrm{mg} / 1$ \\
\hline Toluene solubility & 535 & $\mathrm{mg} / 1$ \\
\hline Xylenes solubility & 175 & $\mathrm{mg} / 1$ \\
\hline Time step at $t=0$ & 0.101 & Day \\
\hline Maximum time step size & 10 & Day \\
\hline Tolerance for concentration change & 0.001 & Day \\
\hline
\end{tabular}




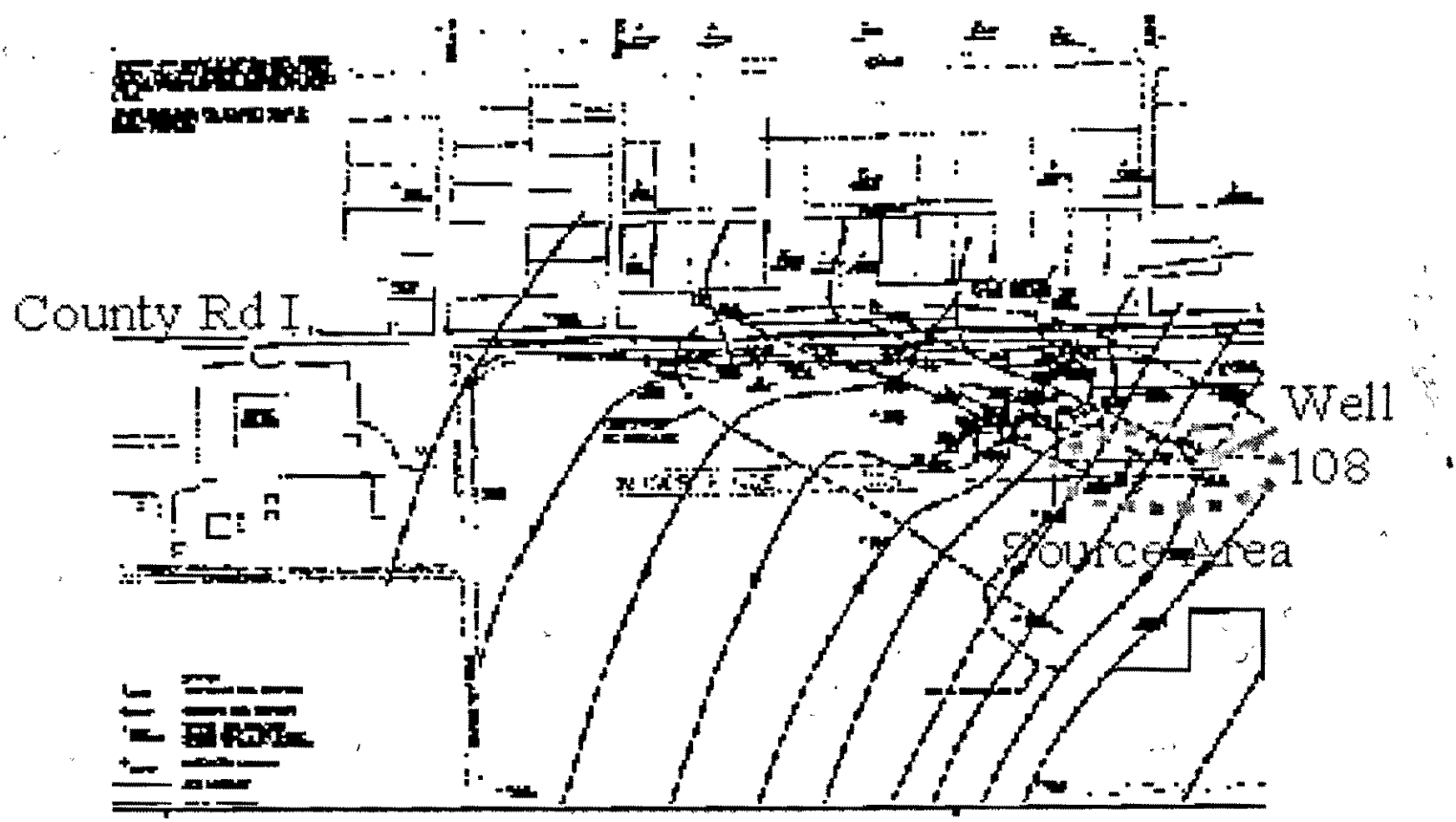

Wgine 7 Sife A.

\section{Site A}

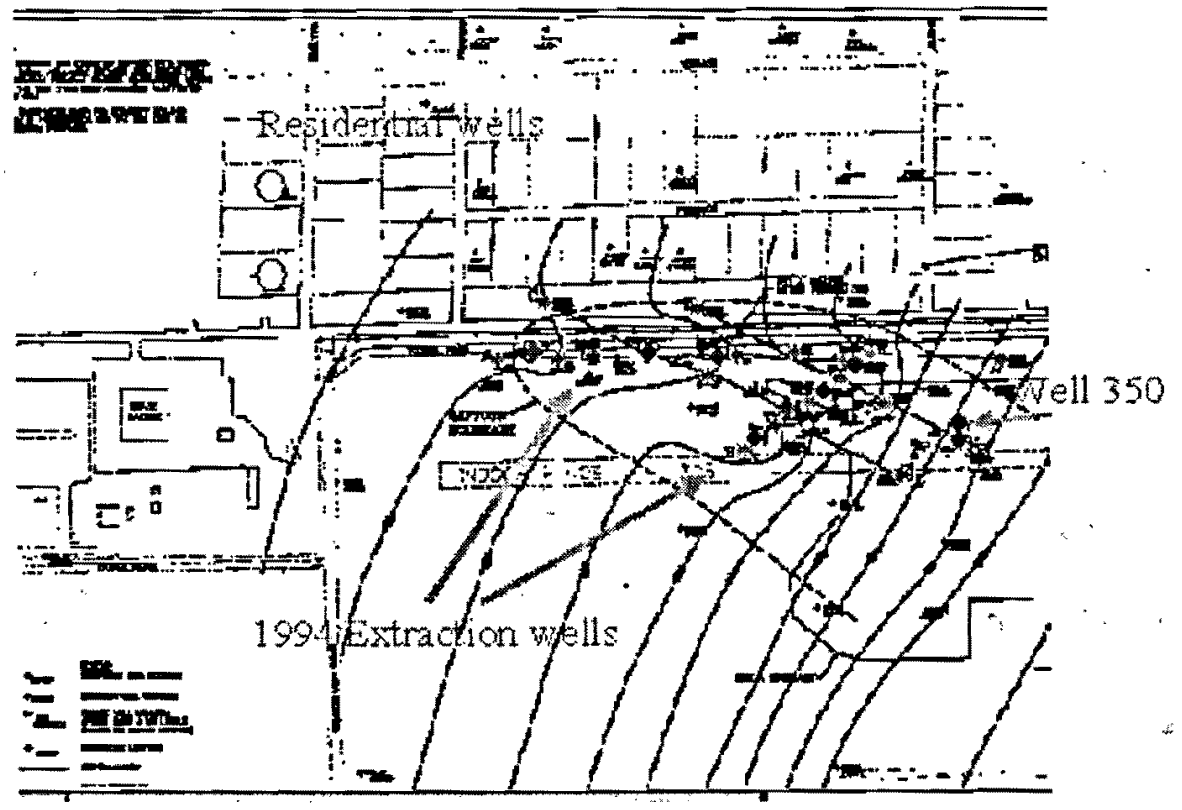

Figure 8 Relationship of two of the resiaental wels (green) to Site A ard the location of the ground water 


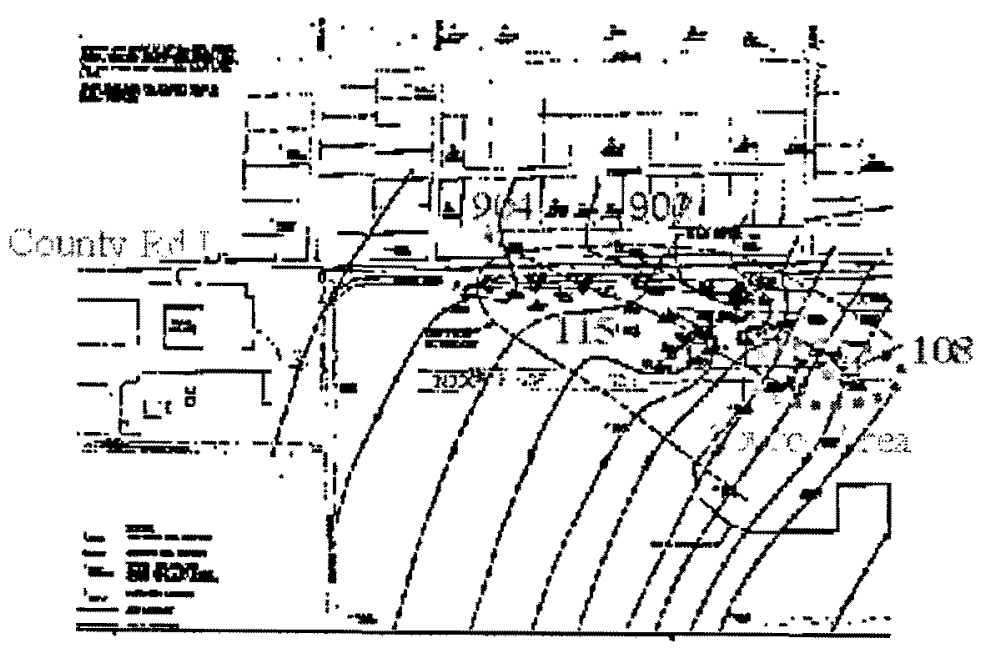

Figure 9 Location of wells that were sampied for the natural attenuation study

\section{Results}

Monitoring wells 01U108, 01U117, 01U115, 01U902, and 01U904 were sampled on three occasions from June, 1997 through June, 1998 as part of this study (Figure 9). In addition, monitoring well 01U067, which is upgradient of the source area, was included as a background monitoring location. It is reasonable to assume that PCE and TCE were the only contaminants released at the site. Thus, the presence of CDCE shows that PCE/TCE is being reductively dechlorinated in the ground water. However, similar to the chemistry of the deep ground water at TCAAP, no vinyl chloride (VC) has been detected in Site A ground water. In addition, no ethene (the ultimate product of reductive dehalogenation) was found at the site from 1997 through 1998. The absence of VC and ethene suggests that the degradation of PCE is incomplete, leading to the accumulation of $\mathrm{CDCE}$ with distance from the source. Table 2 shows the geochemistry of the ground water sampled at Site A from 1997 through 1999. 
Table 2 Gochenistry of the Site A grownd water. Monitoring well 010067 is a background well situated upgradient from the source area ground water.

-WELL NUMBER-

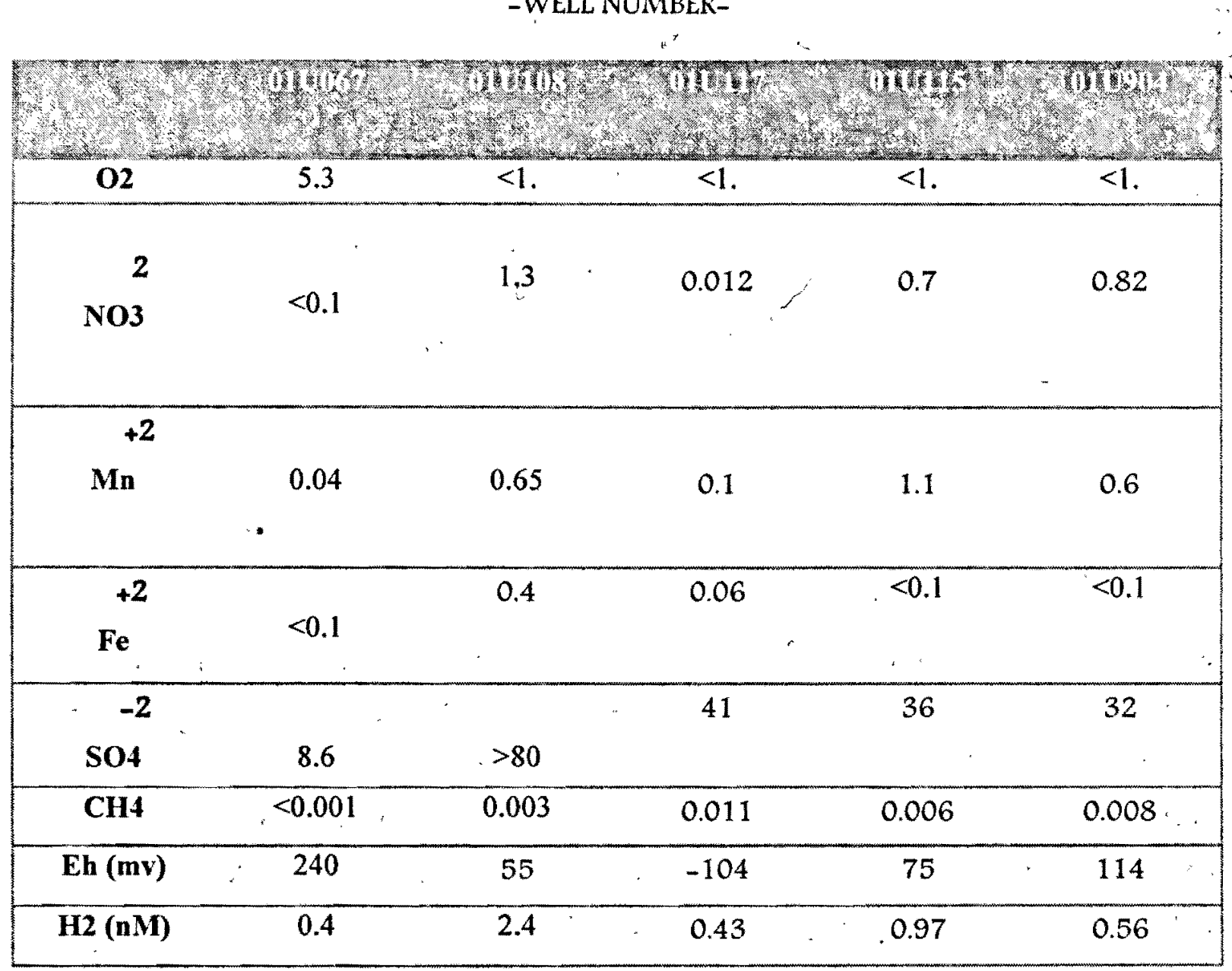

The ground water is manganese reducing from the source area (01U108) to the downgradient well 01U904. The very low concentrations of methane indicate that the ground water is not methanogenic. Ground water hydrogen concentrations are generally in the range of 0.5 to 1.0 nanomolar, indicating that the terminal electron acceptor is probably $\mathrm{Fe}$ (III). This is generally consistent with the geochemistry at the site. However, three ground water samples collected at different times contained hydrogen in excess of 1.0 nanomolar; the highest concentration was 
found at well 010108 at 2.4 nanomolar. These concentrations are indicative of redox conditions consistent with sulfate reduction processes.

These ground water conditions are not generally considered favorable to the reductive dehalogenation of chlorinated aliphatic compounds such as TCE. Nonetheless, the presence of CDCE at this site is evidence that reductive dehalogenation of PCE and TCE is occurring. Thus, it was not clear whether a) natural attenuation is effectively reducing contaminant mass in ground water as it moves away from the source area, or b) if the contaminant degradation stops with $\mathrm{CDCE}$, which simply accumulates in the ground water with distance.

To determine which of the two scenarios is more plausible, we modeled the contaminant plume with the fate and transport model BIOPLUME III to discover whether or not considerable mass removal due to natural attenuation processes is required to account for the observed contaminant concentrations. First, development of the PCE plume was modeled assuming that biological degradation of PCE was negligible. Under this scenario, the effect of the ground water extraction system is included, starting with well 350 in 1988 and continuing with the other eight wells in 1994. In the second simulation, the effect of biological degradation is added. Finally, assuming that the source of contamination will remain constant without intervention, the third simulation includes the effect of source removal in addition to pumping and biological degradation.

\section{Model Simulation 1:}

\section{No PCE Biodegradation with Ground Water Extraction Starting in 1988}

The PCE contaminant plume was modeled using BIOPLUME III using the ground water transport data for the site.but no biodegradation. The model assumes that the initial concentration of PCE in the source area near well $01 \mathrm{U} 108$ was approximately $20 \mathrm{mg} / \mathrm{L}$ in 1950. Records indicate that well 350 began operating in 1988 at approximately $4 \mathrm{gpm}$ and was discontinued in 1994. A second system of eight extraction wells downgradient of the source area was started in 1994 with a combined pumping rate of about $30 \mathrm{gpm}$. The effect of these extraction systems were incorporated in the model. The source area was simulated in 
BIOPLUME III by placing an "injection well" near the source area. The source begins in 1950 at an estimated concentration of $20 \mathrm{mg} / \mathrm{L}$ PCE which gradually decreases to a constant source of 1 $\mathrm{mg} / \mathrm{L}$ to the ground water since 1990. This simulates the actual ground water PCE concentrations in well 014108 since monitoring began in 1985 . Without the contribution of biodegradation, the model predicts that the concentration of PCE would have exceeded 1000 . $\mu \& / L$ downgradient of monitoring well 01 U904 prior to installation of the pumpout well 350 in 1988 (Figures 10 - 15). Further downgradient, the model predicts that in 1994 PCE would " have exceeded concentrations of $200 \mu \mathrm{g} / \mathrm{L}$ in wells 234377 and 5553 (both private wells approximately 1650 feet from the source area). Historical data shows that in 1994, PCE was below detection limits in wells 01U904, 234377 and 5553; only CDCE was found in 234377 at $0.4 \mu \mathrm{g} / \mathrm{L}$. No contamination was discovered in well 5553. This simulation shows that dilution and adsorption cannot account for the actual development of the ground water plume over time. In order to explain the development of the plume at the site, the model must include a mechanism for the in situ destruction of PCE.

\section{PCE Biodegradation Rate Estimate}

Table $3 a$ shows the data collected from the 1998 natural attenuation study. The slope of the regression of PCE as a function of distance is $0.009 \mathrm{ft}-1$, and represents the total attenuation rate $(\mathrm{k})$ of PCE divided by the ground water velocity of $200 \mathrm{ft} \mathrm{yr}-1$. Thus, from the 1998 data, $\mathrm{k}$ $=-1.9 \mathrm{yr}-1$. For comparison, Table $3 \mathrm{~b}$ includes the highest concentrations ever observed in the same wells (1994 Annual Monitoring Report). The slope of the regression from this data is $0.007 \mathrm{ft}-1$, with $\mathrm{k}=-1.4 \mathrm{yr}-1$. The biodegradation rate can be estimated by subtracting the effects of dilution and sorption from the overall attenuation rate

$$
K=|v c / 4 \alpha|\left|[1+(2)(\alpha)|\mathrm{k} / \mathrm{vx}|]^{2}-1\right|
$$

Where

$v c$ - velocity of contaminant transport in ground water, estimated by dividing the ground water velocity by the retardation constant for the site. $R^{*}$. For site A, vc is estimated at $64 \mathrm{ft} / \mathrm{yr} ; \alpha$ = contaminant dispersion in ground water, estimated at $2.5 \%$ or 18 feet for this site; $\lambda$ - rate of 
PCE biodegradation in ground water, and $k$ - the total attenuation rate of -1.9 per year (1998 data. Table $3 a$ ), or -1.4 per year (highest PCE concentrations ever found, Table $3 b$ ). Solving for $\lambda$, the PCE biodegradation rate ranges from -0.5 per year (data fromTable $3 b$ ) to - 0.7, (data from Table $3 \mathrm{a}$ ). Thus, we selected a biodegradation rate estimate of $-0.6 \mathrm{yr}-1$ for PCE at Site A for modeling. Monitoring well location and screen length can have an effect on the accuracy of this rate estimate. Table 4 shows the specifications for the monitoring wells used in this analysis. Most of the wells have 10-15 foot screens. The exception is monitoring well 01U904. which spans the thickness of the aquifer (approx. 25 feet) with a 40 foot well screen. While contaminant concentrations from this well may be diluted to a greater extent than the other wells because of this screen length, dilution cannot account for the absence of PCE at this location or the magnitude of contaminant concentration reduction. Ground water modeling efforts in this study took into account the variations in the aquifer thickness and well screen length

Table 3 Concentrations of PCF as a furtion of distance from the soumce area.

a) 1998 data collected trough the naturat attenuation study, and

b) the highest concertrations observe red

a)

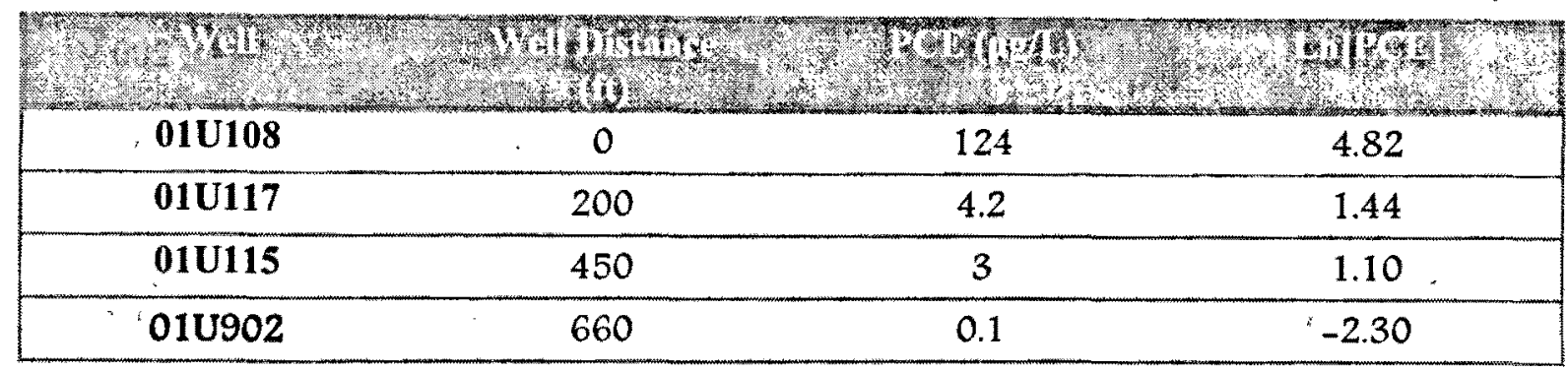

b)

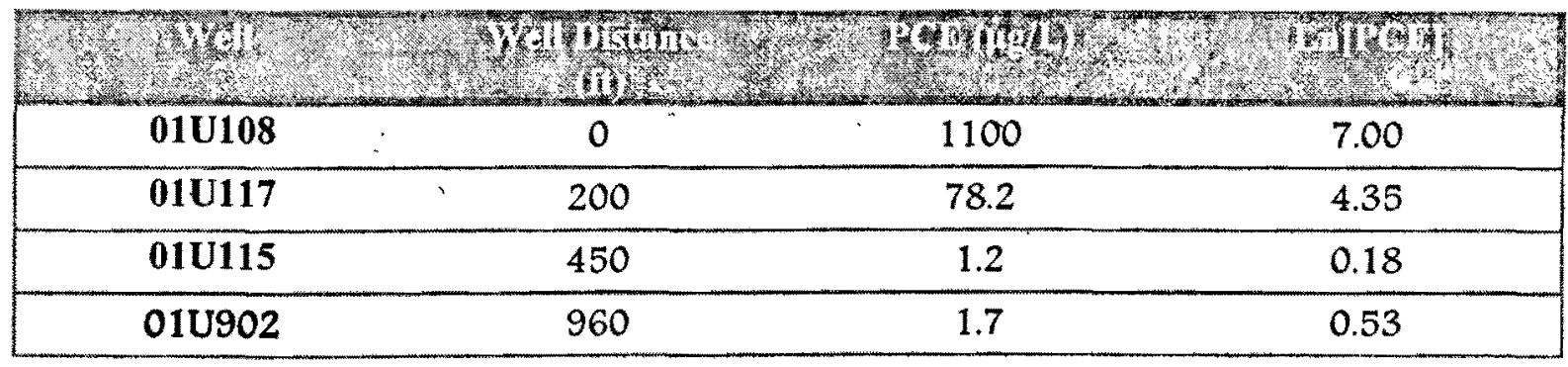




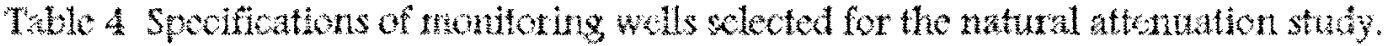

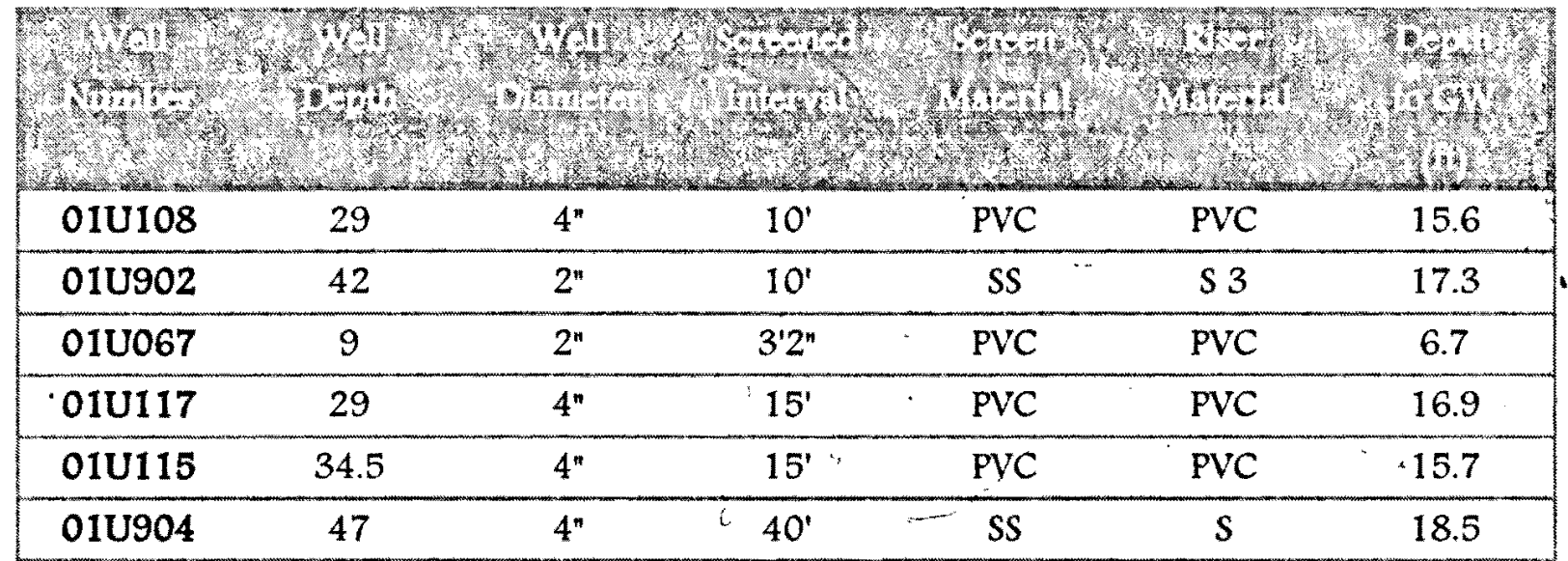

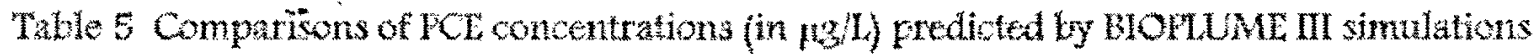
for 1000 with actual 1900 teld data. Simulation 1 is the simulation without biodegradation included; Simulation 2 inchutes biodegradation at $-0.6 \mathrm{per}$ yegr.

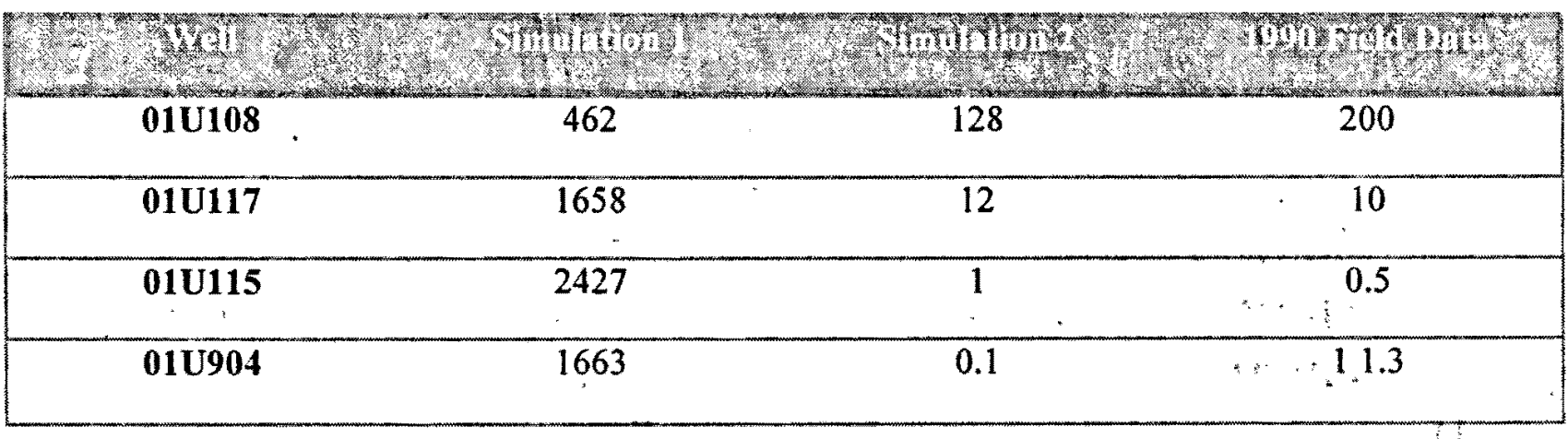




\section{BIOPLUME SIMULATION 1:}

No biodegradation

Pumping starts in 1998

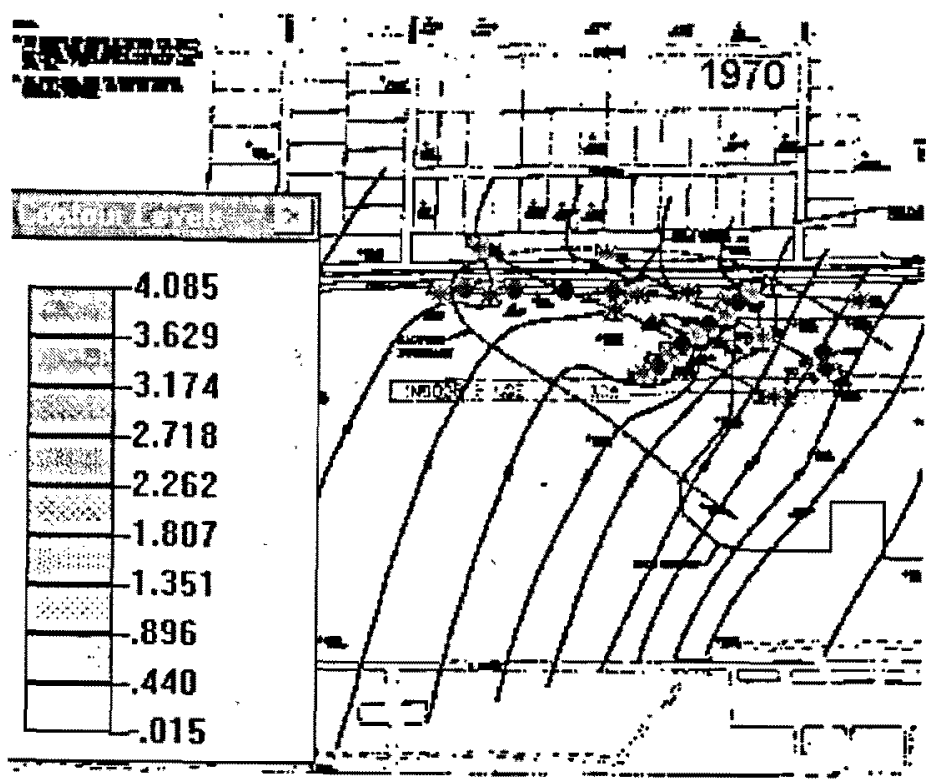

Figure 10 BIOPLUME SMULATION 1.1970

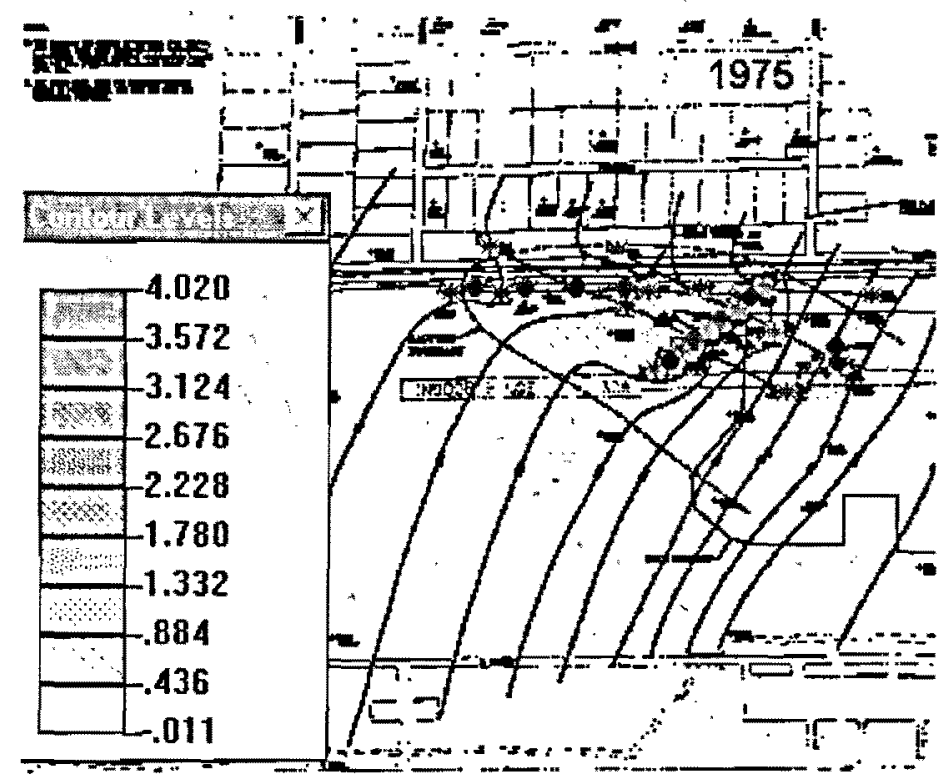

Figure 11 BIOPLUME SIMULATTON 1.1975 


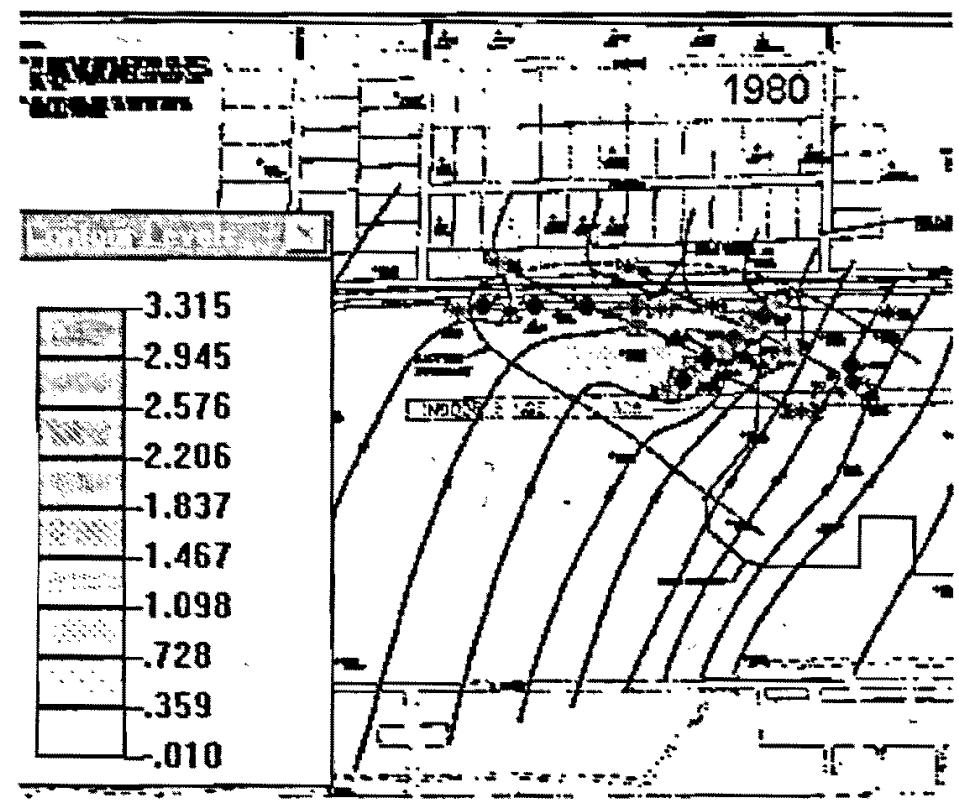

Fgure 12 BIOFLUAE SLIULATION 1.1980

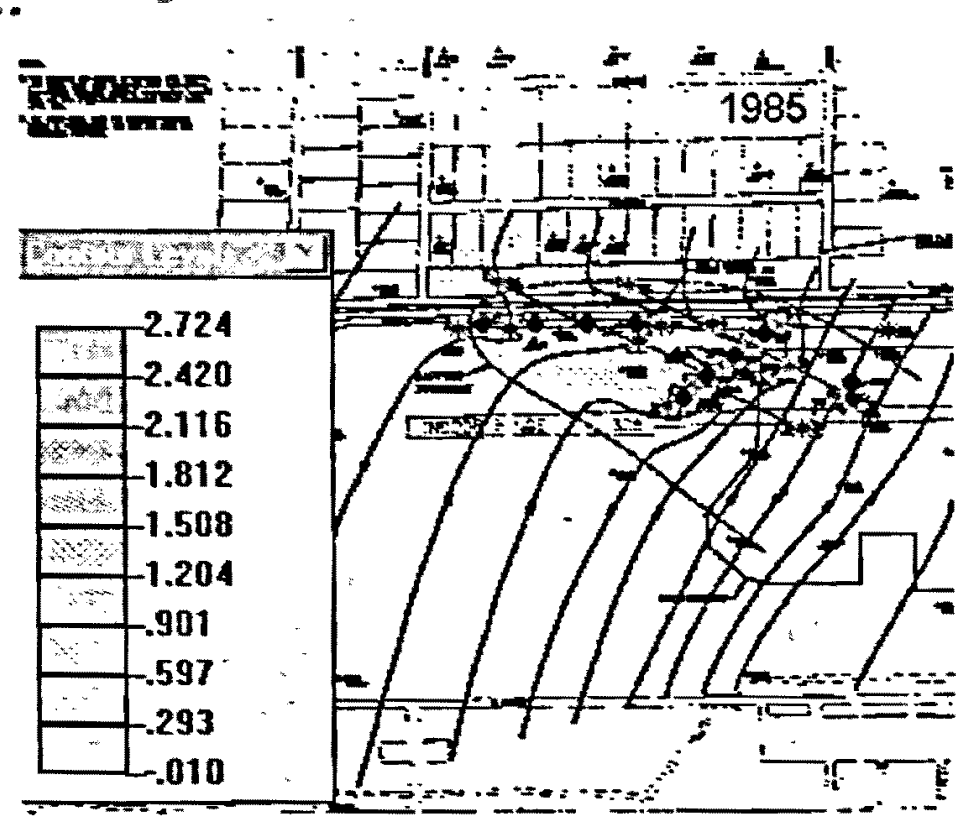

Fgure 13 EIOFLUAE SLIULATION 1.1985 


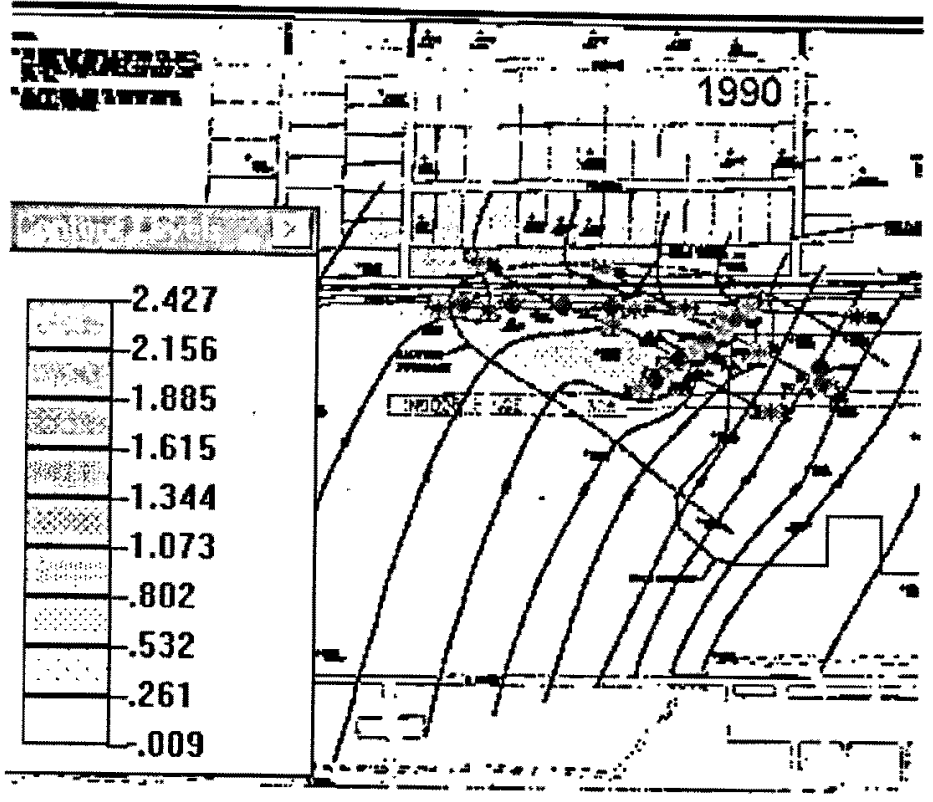

Figra 14 BIOFLUME SMULATON 1.1990

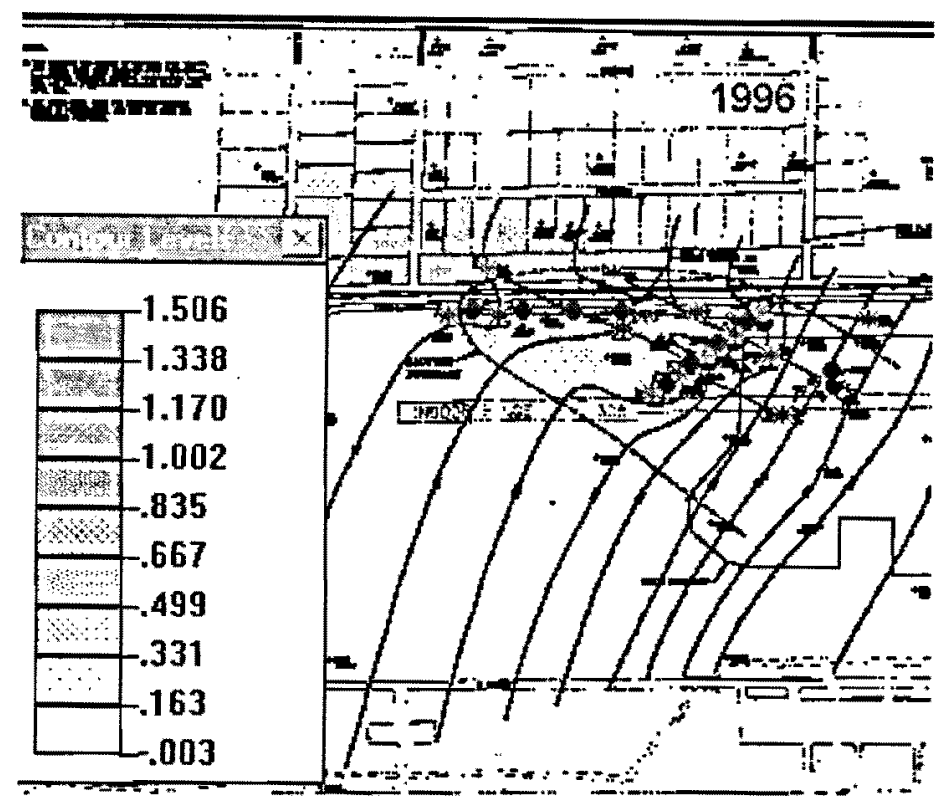

Fgure 15 BIOPLUME SLMUATION 1.1990 


\section{Model Simulation 2:}

\section{Inclusion of Biodegradation at $-0.6 \mathrm{yr}-1$ with Ground Water Extraction Starting in 1988}

In this simulation, BIOPLUME III retains all of the calibrations as in Simulation 1 except that a biodegradation rate of PCE is included at $-0.6 \mathrm{yr}-1$. Under these conditions, the model predicts that concentrations in monitoring well $01 \mathrm{U} 108$ should be approximately $40 \mu \mathrm{g} / \mathrm{L}$ by 1998 . This is similar to the concentrations now observed in well 01U108 (Figures 16-21). This simulation predicts that the PCE plume should reach monitoring well $01 \mathrm{U} 115$ at $3 \mu \mathrm{g} / \mathrm{L}$ in 1998; no PCE should be found in monitoring well 01U904, and no PCE is expected to migrate beyond well 01 U90 4 over the entire 50 years of plume development. This is in contrast to Simulation 1 which predicted that, without the effect of biodegradation. PCE should have migrated 1600 feet downgradient of the source area at concentrations greater than $200 \mu \mathrm{g} / \mathrm{L}$. Simulation 2 accurately describes the development of the plume at Site $A$.

Assuming that the source area is not actively remediated and remains constant from now on the model predicts that these PCE concentrations should remain constant in ground water in the future.

$$
R=1+(\mathrm{p})(K o c)(\text { foc }) / \mathrm{n}
$$

where $\mathrm{p}, n$, and $f o c$ are estimated at $1.7 \mathrm{~g} / \mathrm{cm} 3,0.25$, and 0.001 , respectively. The literature value for $K o \mathrm{C}$ $P C E$ is $370 \mathrm{~L} / \mathrm{Kg}$. 


\section{BIOPLUME SIMULATION 2:}

Biodegradation at -0.6 per year.Pumping starts in 1998

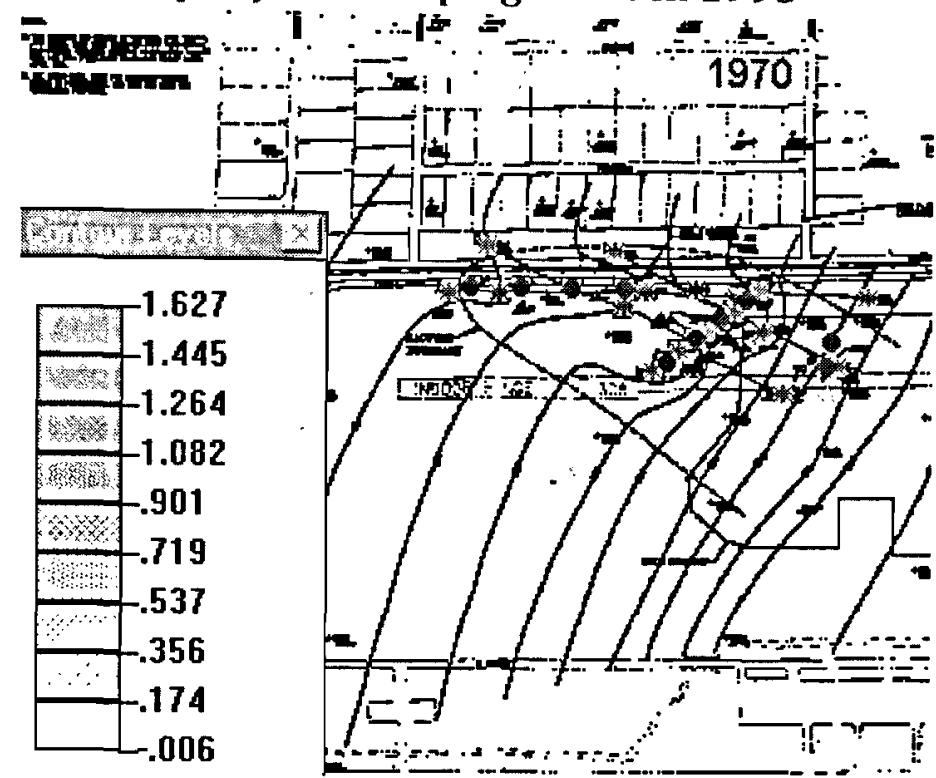

Figure 16 BIOFLUME SIMULATION 2, 1970

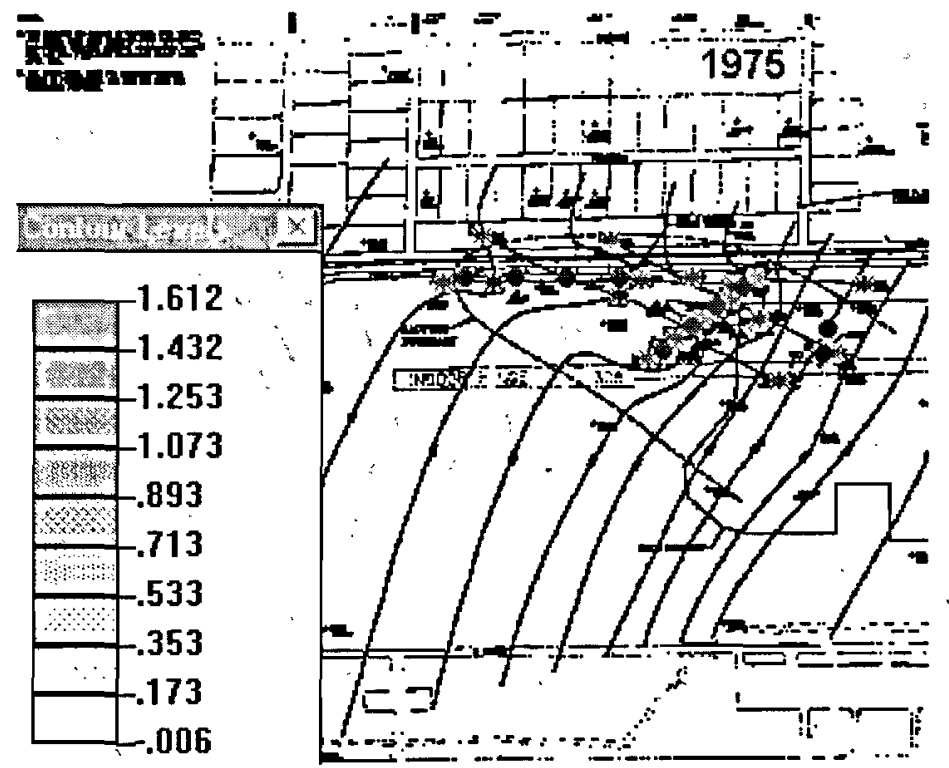

Figure 17 BIORLME SMULATION 2: 1975 


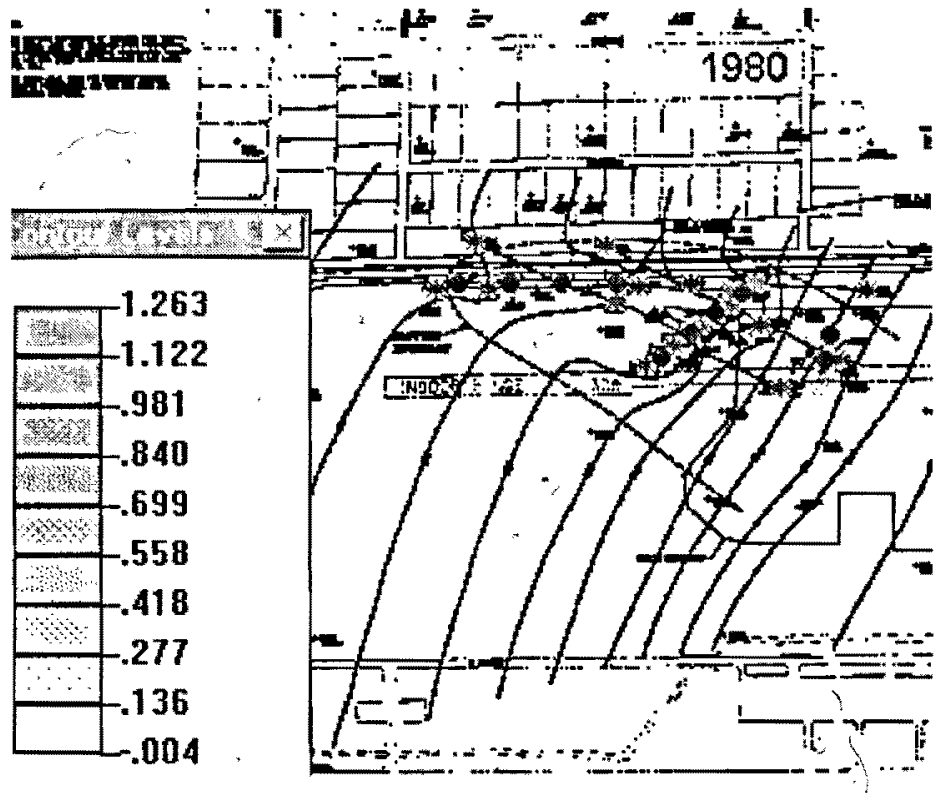

FiguTe 18 BOPLUME SMULATION 2,1980

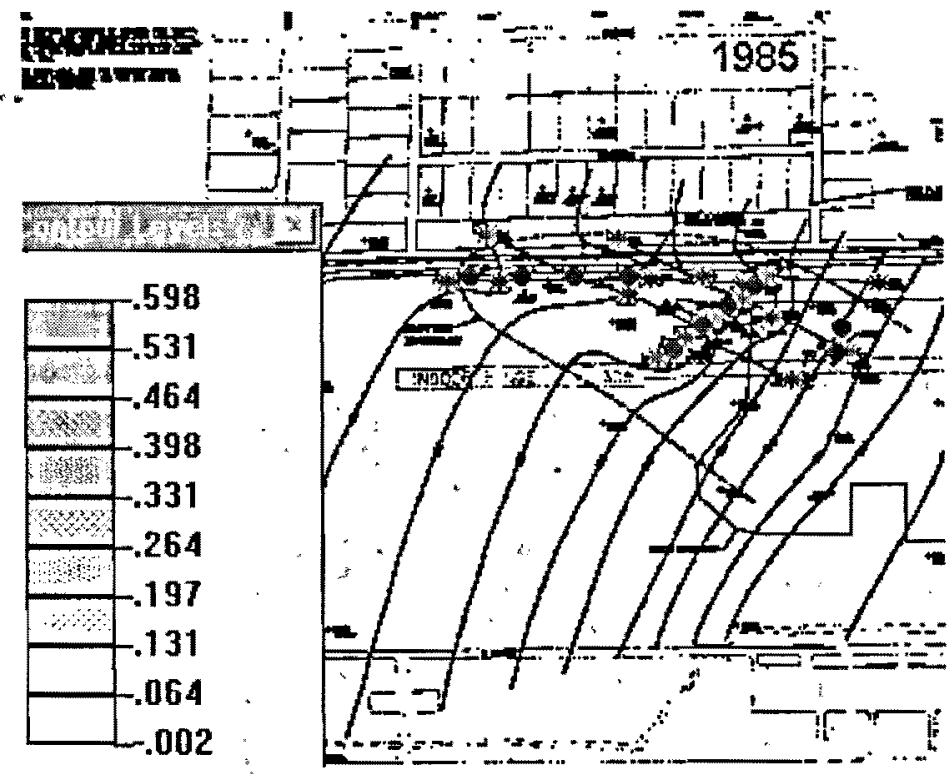

Figr 19 BIOPLUME SLUULATON 2. 1985 


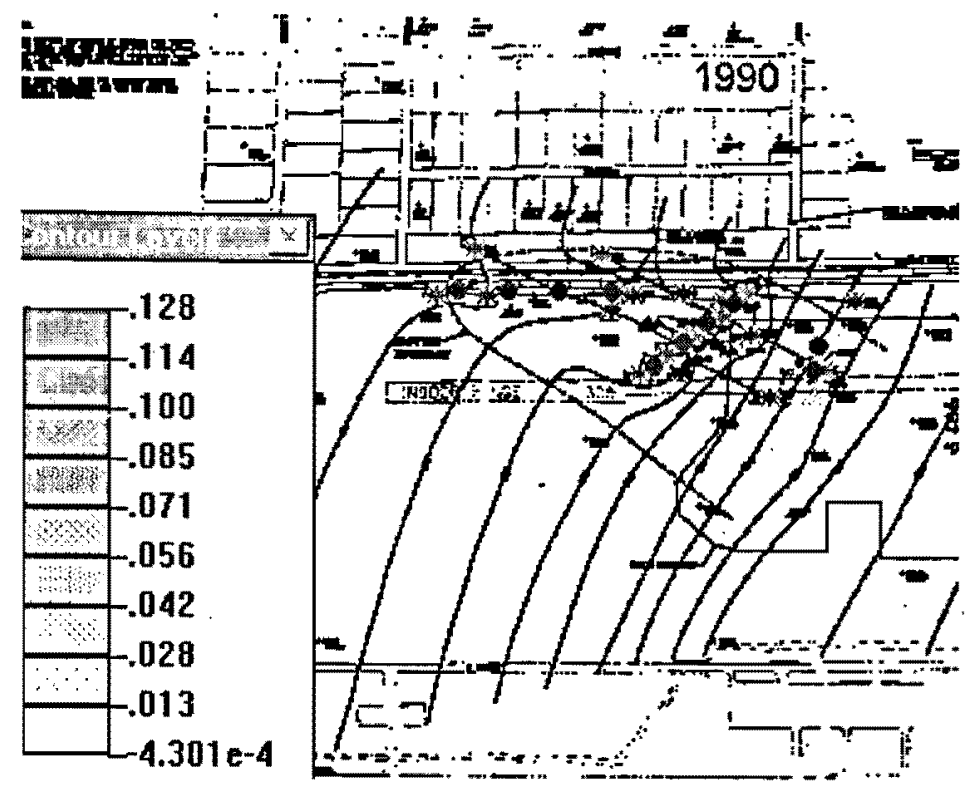

PGuTE 20 BIOHLUME SMULATON 2,1990

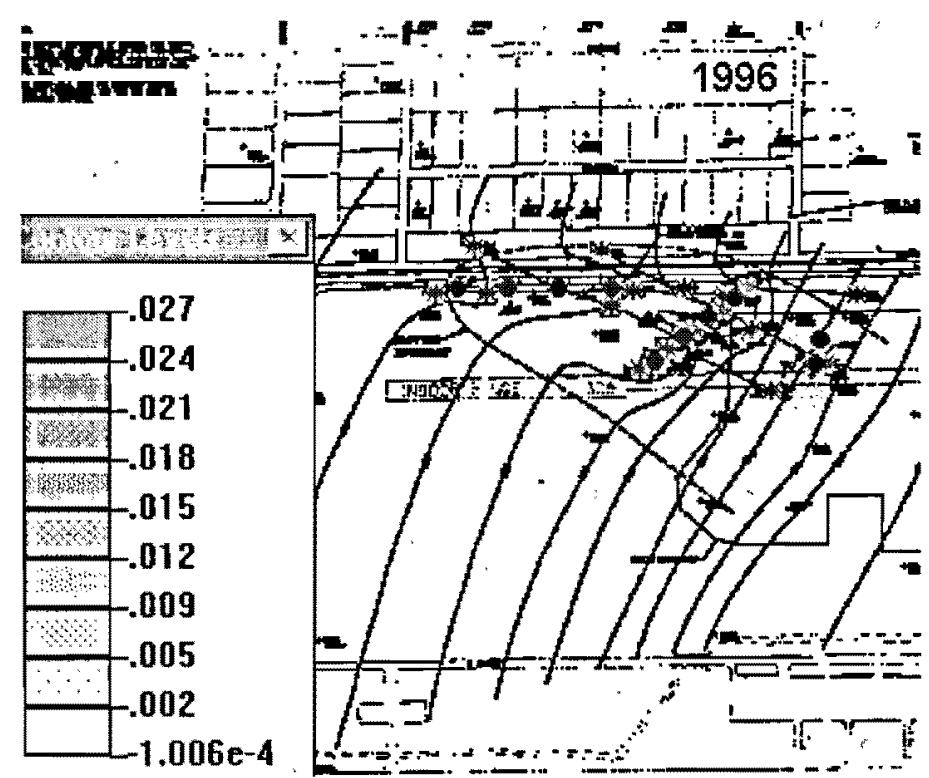

Fsture 21 BOPLUME SMULATION 21996. 
Model Simulation 3:-Biodegradation at $-0.6 \mathrm{yr}-1$ with Ground Water Extraction Starting in 1988 Complete Source Removal in 2000

In the previous two simulations, the source of PCE to the aquifer is assumed constant after 1990. With biodegradation and pumping included, the model predicts that PCE concentrations in the ground water will remain at approximately $40 \mu \mathrm{g} / \mathrm{L}$ in monitoring well $01 \mathrm{U} 108$, with the plume extending a distance of approximately 420 feet from the source area. These concentrations would remain unaltered as long as the source of contamination is unaffected. Army has proposed a combined soil vapor extraction and ground water sparging system in the source area near monitoring well $01 \mathrm{U} 108$ to eliminate any remaining contribution of PCE to the ground water. Simulation 3 includes the effect of a $90 \%$ source removal at Site A in 2001 while maintaining the initial release assumptions, the biological degradation rate, ground water transport parameters, and the effects of pumping that were included in the previous simulations (Figures 22-25). This was accomplished in BIOPLUME III by reducing the injection concentration (which simulates the source in the model) by $90 \%$. The model shows that once the source of PCE is gone, the PCE contaminant plume should collapse rapidly (provided that the biodegradation rate is not adversely affected by ground water aeration), with ground water concentrations below $3 \mu \mathrm{g} / \mathrm{L}$ by 2005 . 
BIOPLUME SIMULATION 3:Biodegradation at $\mathbf{- 0 . 6}$ per year.Pumping starts in $1998.90 \%$ Source removal in 2001

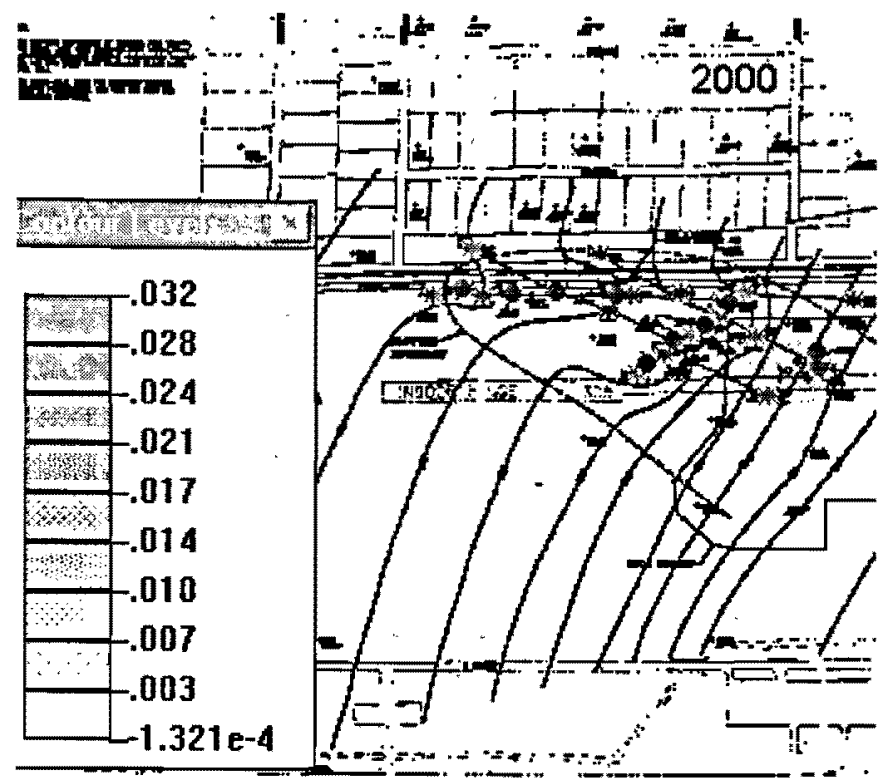

Figure 22 BOTLUME SIMULATION $3: 2000$

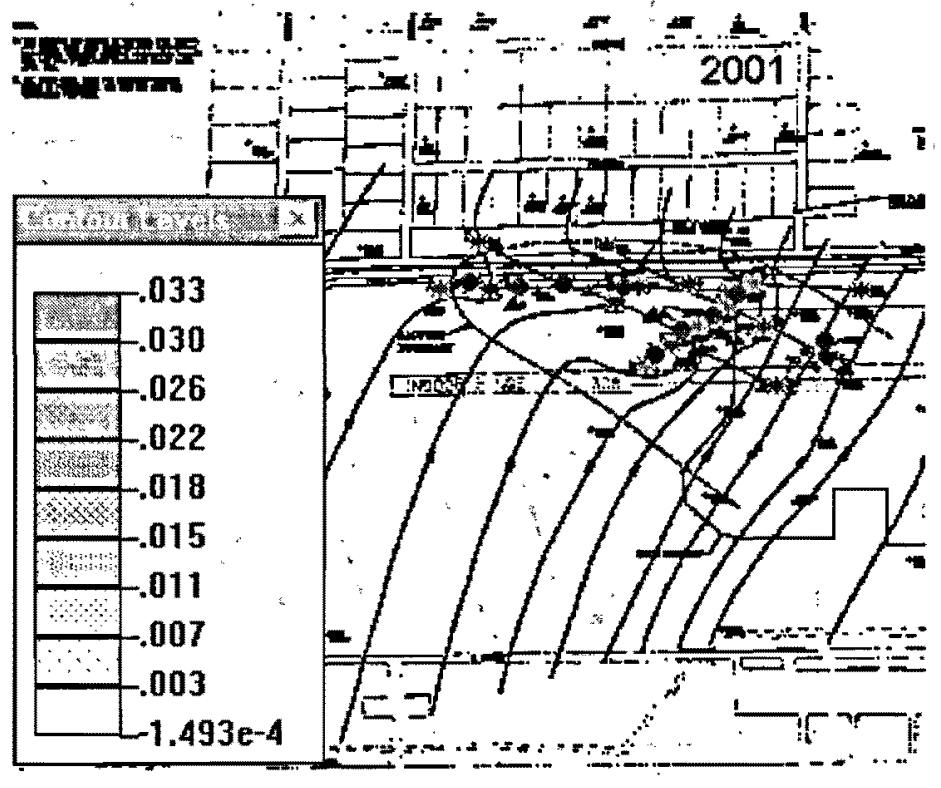

Nigure 23 BROFUME SIMULATION 3:2001 


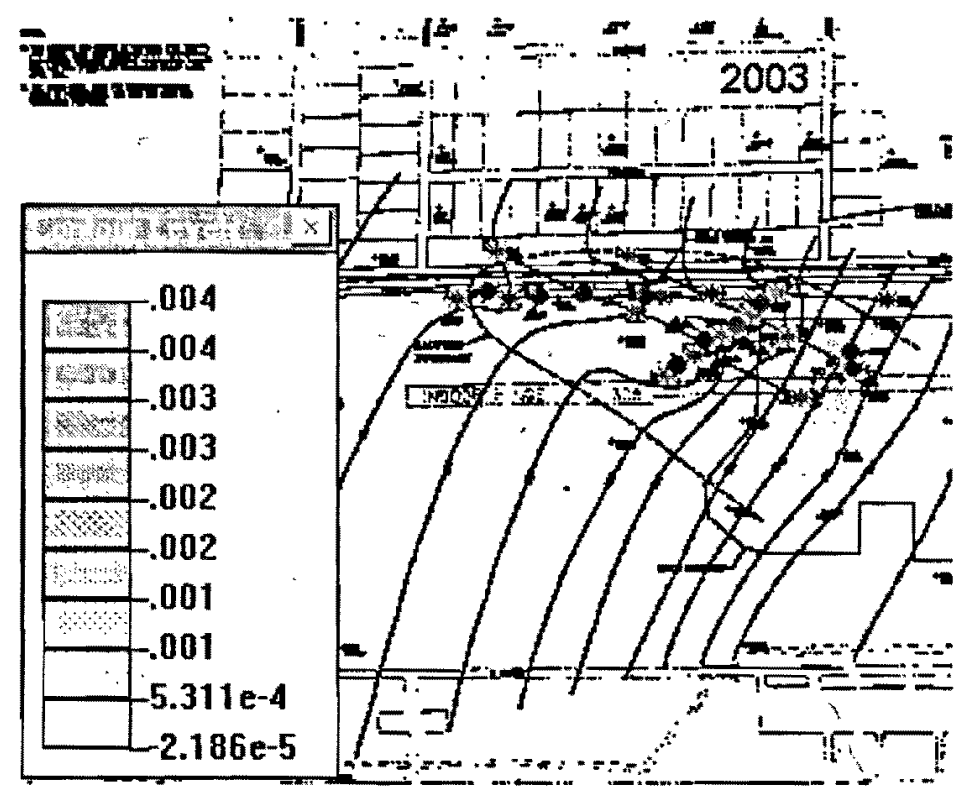

HgTM 24 BOHUME SIMULATON 3.2003

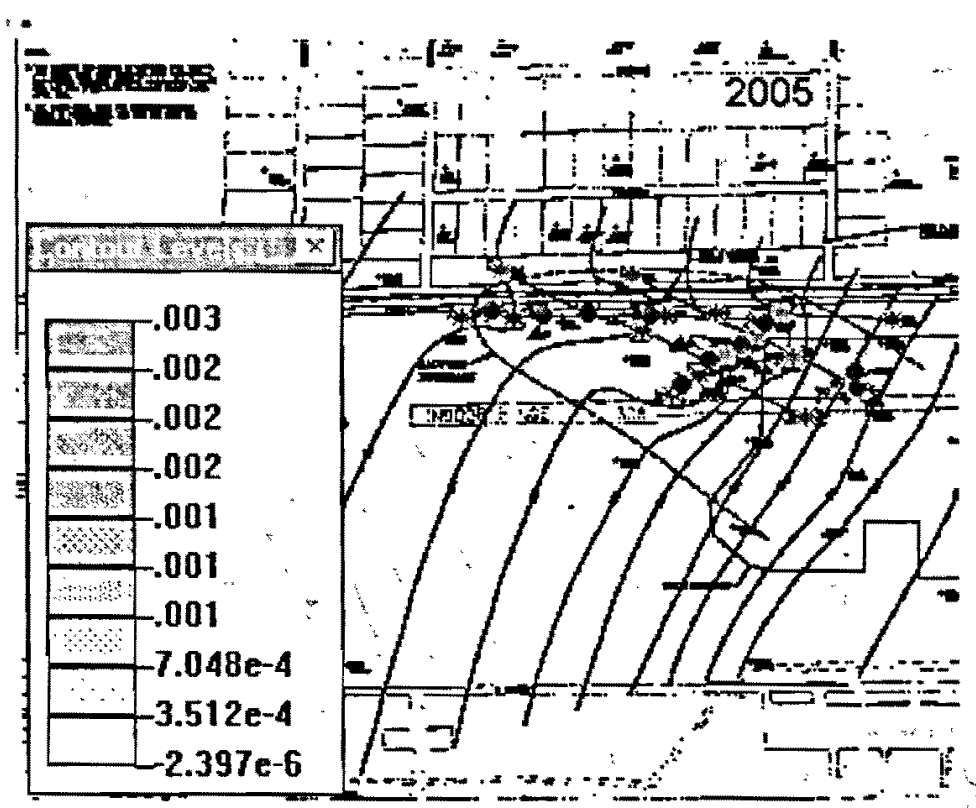

Figure 25 BTOLLUE SMULATION 3.2005 


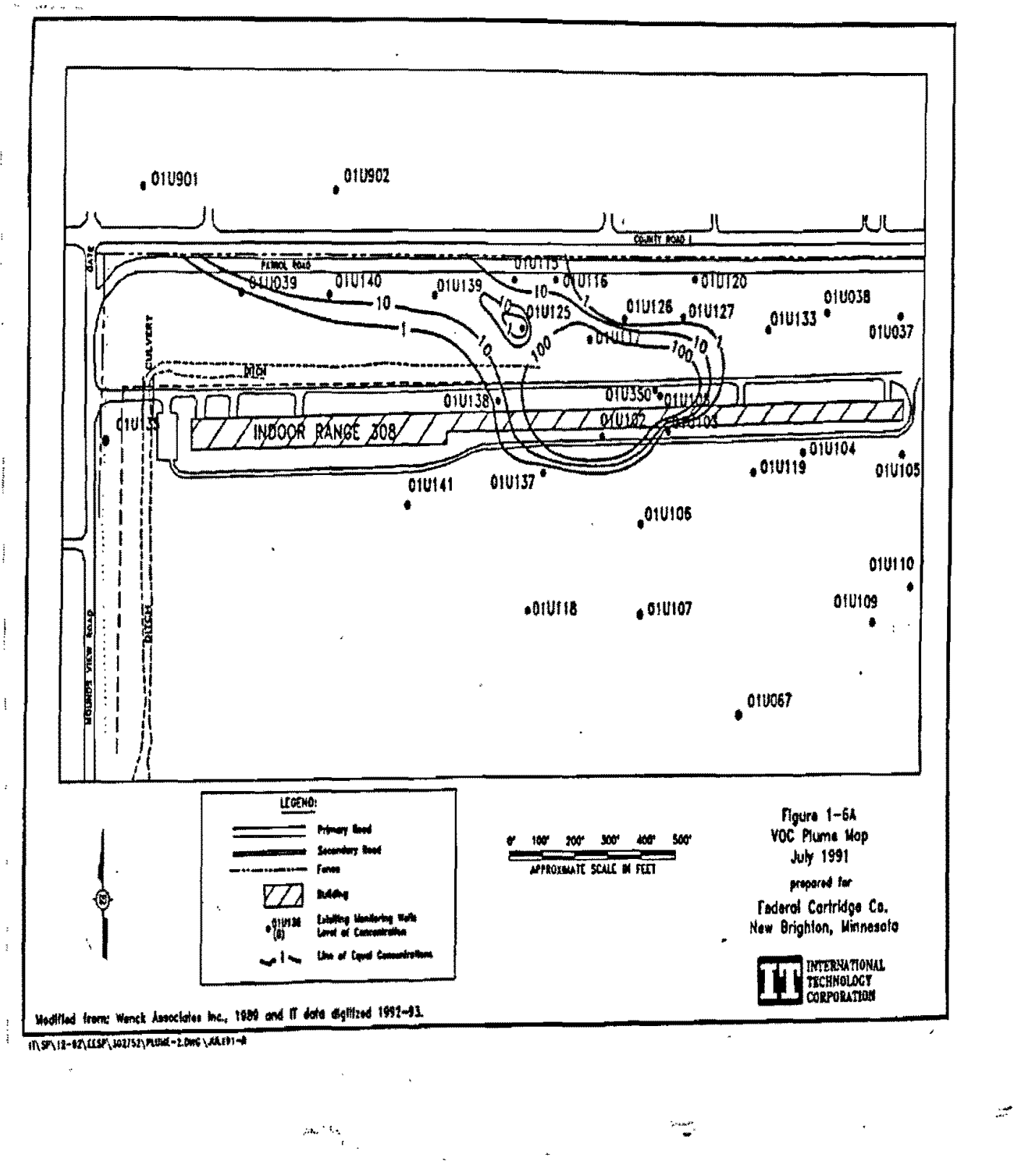

Figure 26 Isoconcentration Map 


\section{Well 010108}

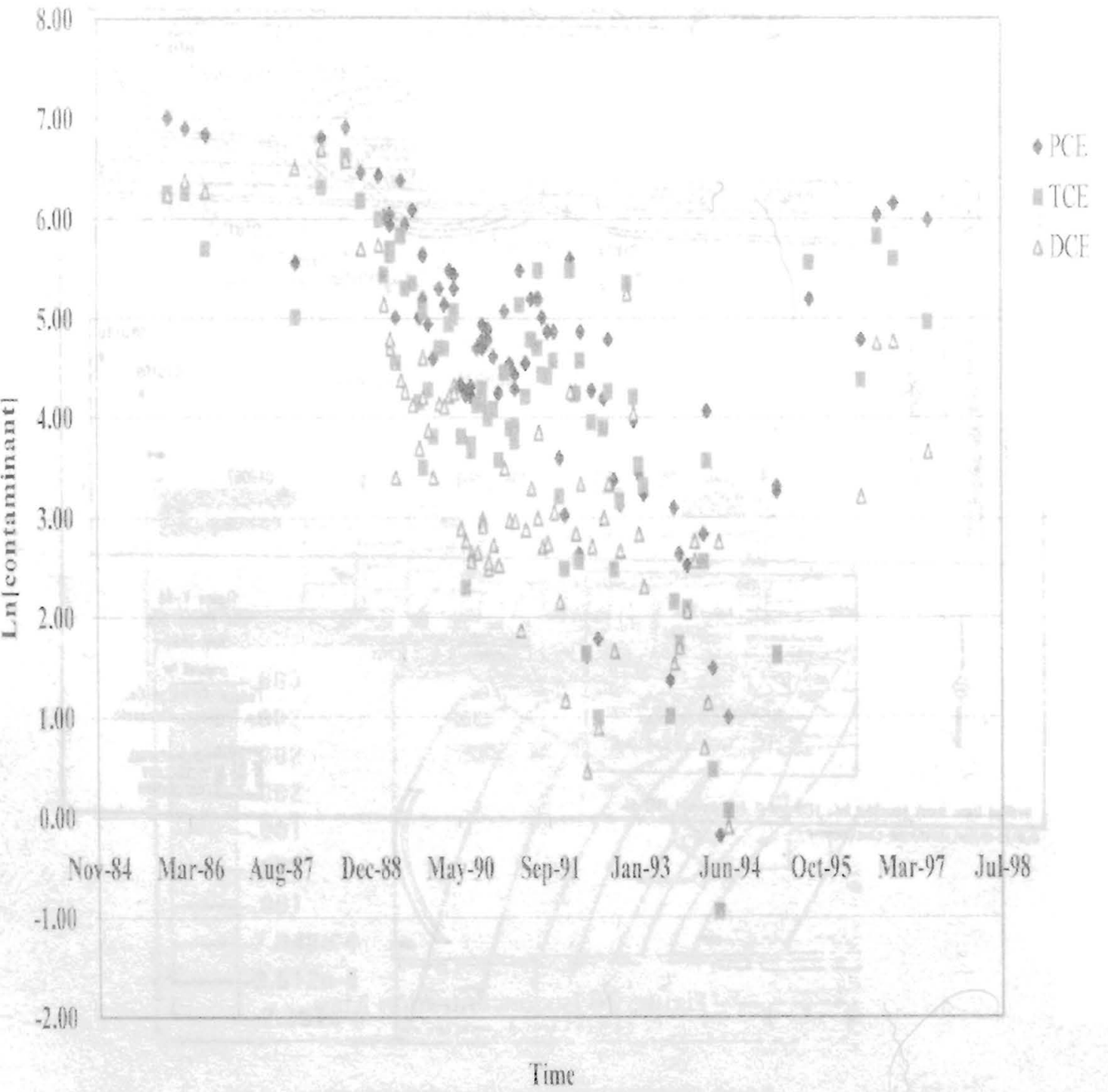

Figure 27 Contaminant Trends vs. Time in Monitoring Well o1U108 


\section{Well 010117}

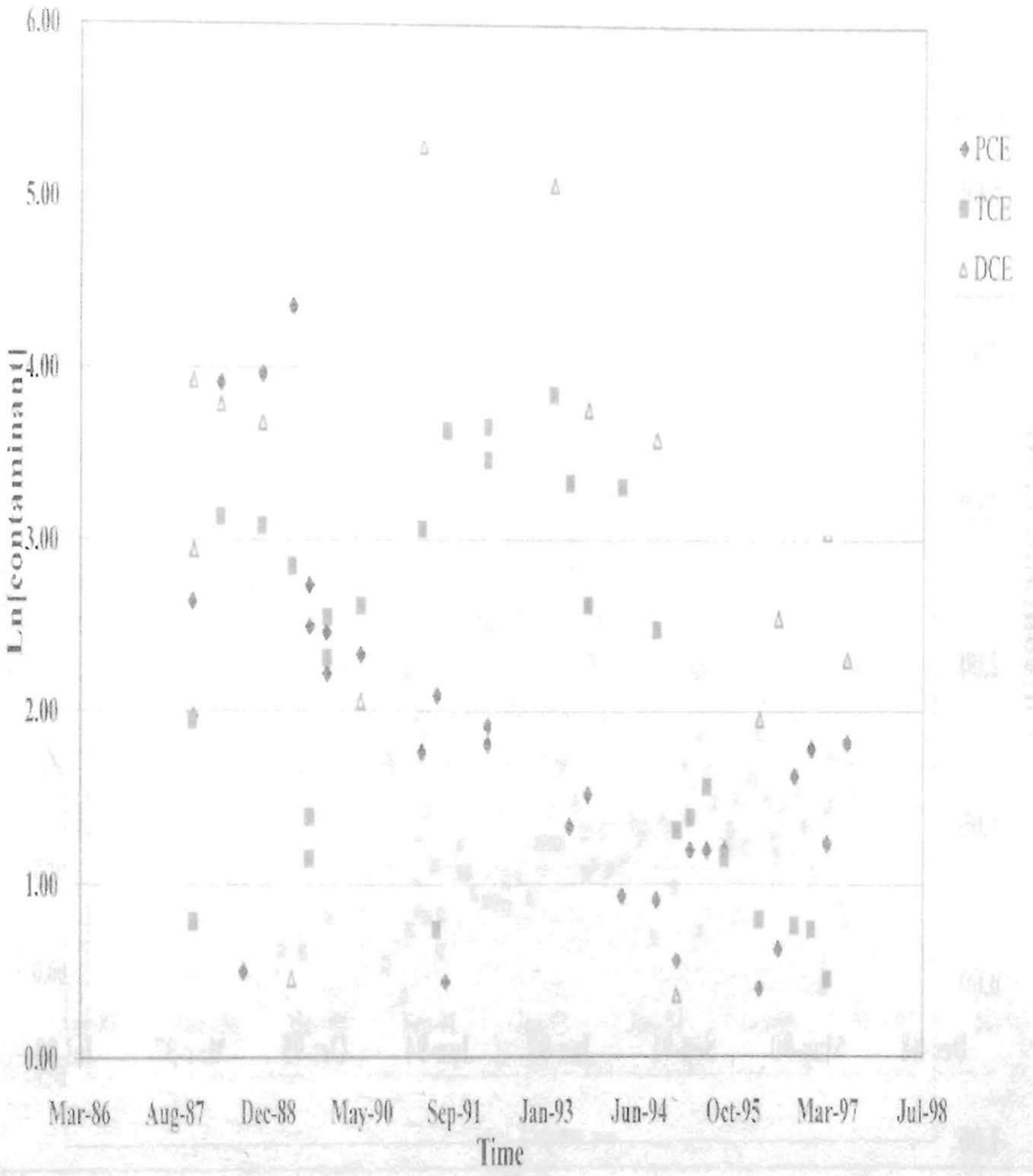




\section{Well 011902}



Figure 29 Contaminant Trends vs. Time in Monitoring Well 01 U902 


\section{Well 011115}

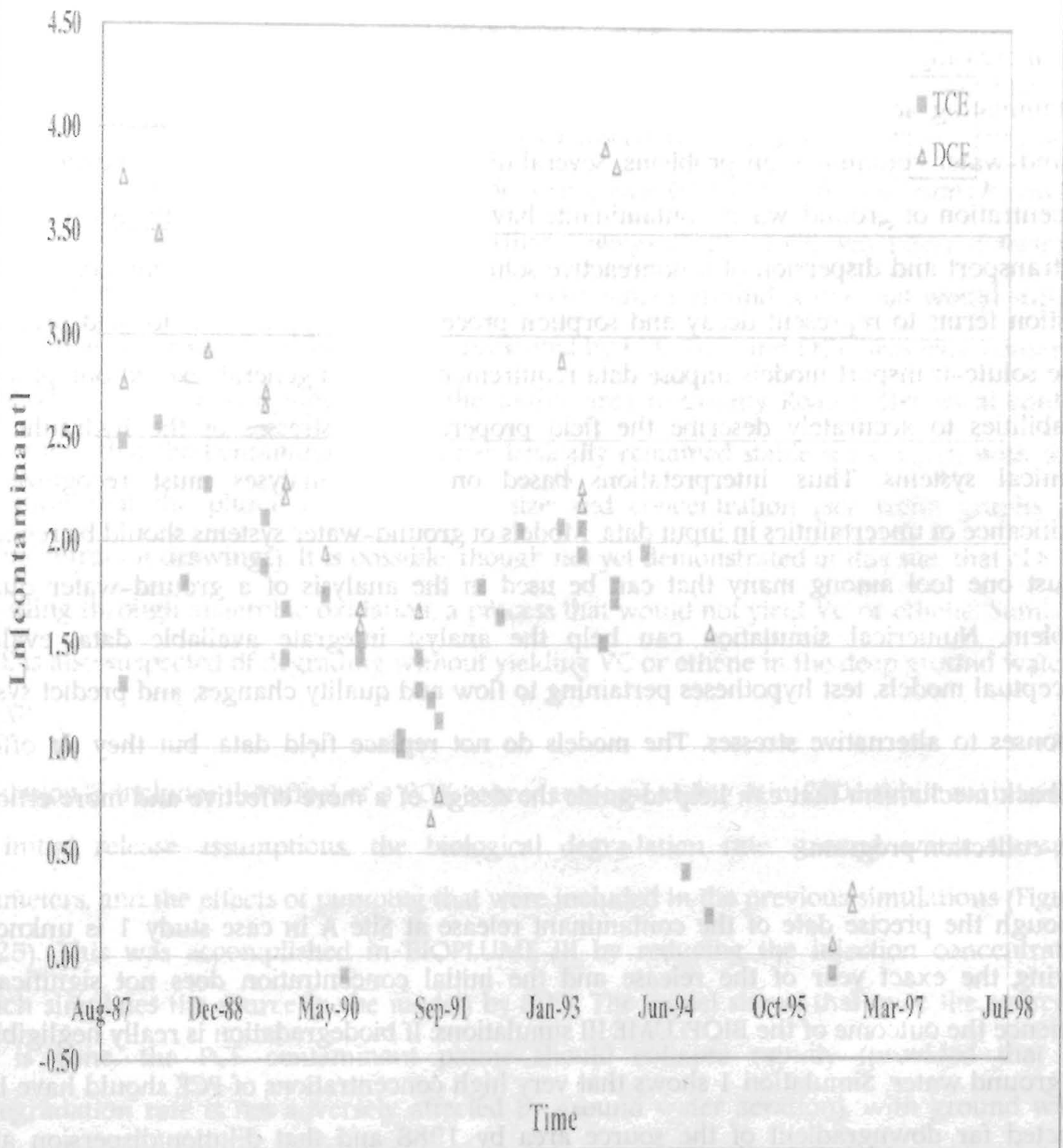

Figure 30 Contaminant Trends v3. Time in Monitoring Well $01 U 115$ 


\section{CHAPTER 6}

\section{DISCUSSION \& CONCLUSION}

The increasing public awareness and concern about the hazards of toxic chemicals contaminating aquifers has created an increased necd for predictive capabilities to analyze ground-water contamination problems. Several digital models to simulate the movement and concentration of ground-water contaminants have been documented recently. Most simulate the transport and dispersion of a nonreactive solute, but some include mathematically simple reaction terms to represent decay and sorption processes. For applications to field problems, these solute-transport models impose data requirements that, in general, exceed our practical capabilities to accurately describe the field properties and stresses of the hydraulic and chemical systens. Thus, interpretations based on model analyses must recognize the significance of uncertainties in input data. Models of ground-water systems should be regarded as just one tool among many that can be used in the analysis of a ground-water quality problem. Numerical simulation can help the analyst integrate available data, evaluate conceptual models, test hypotheses pertaining to flow and quality changes, and predict system responses to alternative stresses. The models do not replace field data, but they do offer a feedback mechanism that can help to guide the design of a more effective and more efficient data-collection program.

Although the precise date of the contaminant release at Site A in case study 1 is unknown, varying the exact year of the release and the initial concentration does not significantly influence the outcome of the BIOPLUME III simulations. If biodegradation is really negligible in the ground water, Simulation 1 shows that very high concentrations of PCE should have been detected far downgradient of the source area by 1988 and that dilution/dispersion alone cannot account for the difference between observed concentrations and those predicted by BIOPLUME III. Incorporating a biodegradation rate of $-0.6 \mathrm{yr}-1$ is required to simulate the 
reduction in the PCE concentrations with distance to levels observed in the past 10 ycars (Table 4).

In addition, the PCE breakdown products. TCE and CDCE, are not accumulating with distance in the ground water (see trend graphs for indvidual wells,). The loss of TCE can be attributcd to its dehalogenation to $C D C E$. The fate of $C D C E$ in the ground water is less clear: VC and ethenethe products of $\mathrm{CDCE}$ reductive dehalogenation - were never detected in ground water samples, indicating that $\mathrm{CDCE}$ is not reductively dehalogenated at this site. However, historical data show that the highest concentrations of $C D C E$ discovered in the downgradient arca of the plume were in the range of $100 \mu \mathrm{g} / \mathrm{L}$ in monitoring well 01U902, with defections below the HRL in private wells 234377 and 5553 further downgradient. CDCE was never detected at concentrations in the range of $1000 \mu \mathrm{g} / \mathrm{L}$ in downgradient ground water that would support the idea that the mass of contaminants, represented by PCE, TCE, and DCE, was ever conserved in the ground water as it moved from the source area to County Road I. Historical contour maps show that the contaminant plume has basically remained stable since 1991, with some indication that the plume is shrinking in size and concentration (see trend graphs and isoconcentration drawings). It is possible, though not yet demonstrated at this site, that CDCE is degrading through anaerobic oxidation, a process that would not yield VC or ethene. Similarly, CDCE is also suspected of degrading without yielding $v^{\prime} C$ or ethene in the deep ground water at TCAAP

Simulation 3 includes the effect of a 90\% source removal at Site A in 2001 while maintaining the initial release assumptions, the biological degradation rate, ground water transport parameters, and the effects of pumping that were included in the previous simulations (Figures 22-25). This was accomplished in BIOPLUNE III by reducing the injection concentration (which simulates the source in the model) by $90 \%$. The model shows that once the source of PCE is gone, the PCE contaminant plume should collapse rapidly (provided that the biodegradation rate is not adversely affected by ground water aeration), with ground water concentrations below $3 \mu \mathrm{g} / \mathrm{L}$ by 2005 . 
REMGRES

Ground water contamination. Transport \& Remediation, sccond edition, Philip B.Bedicnt, Hanadi S. Rifai, Charles J. Newell, Prentice Hall PTR, Upper Saddle River, New Jersey.

Bradley, P.M., F.H. Chapelle, and J.T. Wilson. 1997. Field and laboratory evidence of intrinsic biodegradation of vinyl chloride contamination in a Fe(III)-reducing aquifer. J. Contaminant Hydrol. 31:111-127.

Bradley, P.M. J.E. Landmeyer, and R.S. Dinicola. 1998. Anacrobic oxidation of [1,214Cldichloroethene under Min(IV)-reducing conditions. Appl. Environ. Microbiol. 64:15601562. 3. Buscheck, T.E., and C.M. Alcantar. 1995. Regression techniques and analytical solutions to demonstrate intrinsic bioremediation. In: Intrinsic Bioremediation, Hinclee, R.E., J.T. Wilson, and D.C. Downey, Eds. Batelle Press, Columbus, OH. pp. 109-116.

Chapelle, F.H., and P.M. Bradley. 1999. Selecting remediation goals by assessing the natural attenuation capacity of ground water systems. Biorem. J. 2:227-238.

Federal Cartridge Co., Wenck Associates, Inc., Alliant Techsystems, Inc., and Conestoga-Rovers and Associates, LTD. Installation Restoration Program: Twin Cities Army Ammunition Plant. Fiscal Year 1994 Annual Monitoring Report. Final Report. September, 1995.

International Technology Corp. Aquifer Test, Site A, Twin Cities Army Ammunition Plan, New Brighton, Mimesota. August, 1992.

Lovley, D.R. F.H. Chapelle, and J.C. Woodward. 1994. Use of dissolved H2 concentrations to determine distribution of microbially catalyzed redox reactions in anoxic groundwater. Environ. Sci. Technol. 28, 1205-1210.

U.S. Environmental Protection Agency. 1998. Technical Protocol for Evaluating Natural Attenuation of Chlorinated Solvents in Ground Water. EPA/600/R-98/128. 9. U.S. Army Corps of Engineers. Installation Restoration Program: Remedial Investigation Report for the Twin Cities Army Ammunition Plant. Toxic and Hazardous Materials Agency. April, 1991. 
U.S. Environmental Protection Agency. 1999. Evaluation of Natural Attenuation of Chlorinated Solvents in Ground Water at the Twin Cities Army Ammunition Plant.

U.S. Environmental Protection Agency. BIOPLUME III: Natural Attenuation Decision Support System. EPA/600/R-98/010.

Predicting Benzene Transport in Subsurface under Uncertainty through a Coupled Monte Carlo and Factorial Analysis Approach,C. CHEN,1 G. YAN,1 AND S. GUO1, 1State Key Laboratory of Heavy Oil Processing, China University of Petroleum, Beijing, China

UVQ, A tool for assessing the water and contaminant balance impacts of urban development scenarios, V G Mitchell, C Diaper CSIRO Urban Water, PO Box 56, Highett, Vic 3190, Australia An Analysis of site parameters affecting natural attenuation in saturated soil thesis, William $\mathrm{H}$. Potts, Captain, USAF AFIT/GEE/ENV/93S-12

Natural Attenuation Decision Support System User's Manual Version 1.0, by Hanadi S. Rafai,et al.

Simulations for Groundwater Remediation Using Three Remedial Techniques,Hund-Der and Jun-Liang Chen, Institute of Environmental Engineering National Chiao-Tung University Hsinchu, Taiwan, ROC.

Proposed air force guidelines for successfully supporting the intrinsic remediation (natural attenuation) option at fuel hydrocarbon contaminated sites. Todd $\mathrm{H}$ Wiedcrmeier, John $\mathrm{T} \&$ Donald H. Kampbell, Air force centre for envirommental excellence, Brooks air force base, Taxes.

Numerical Transport Model of Chlorinated Organic Compounds in Saturated Porous Media,by Budi KURNIAWAN and Kenji JINNO. Memoirs of the Faculty of Engineering, Kyushu University, Vol.66. No.2, June 2006 
Organic Chemicals in Groundwater, Modeling Fate and Transport, Mark N. Goltz, Jae-Woo Park, Peter P. Feng and Harold C. Young

Environmental Impact Assessment of Recycled Wastes on Surface and Ground Waters; Engineering Modeling and Sustainability, Tarek A. Kassim

Groundwater Flow Models ,C. P. Kumar, Scientist 'E1' National Institute of Hydrology Koorkee247667 (Uttaranclial)

http://www.epa.gov/swerustl/cat/landfarm.htm 